\title{
th. $305^{-}$
}

BNL 50822

ENERGY SYSTEMS STUDIES PROGRAM

ANNUAL REPORT

FISCAL YEAR 1977

M. Beller, Editor

JANUARY 1978

Prepared for the

UNITED STATES DEPARTMENT OF ENERGY

by the

NATIONAL CENTER FOR ANALYSIS OF ENERGY SYSTEMS

BROOKHAVEN NATIONAL LABORATORY

ASSOCIATED UNIVERSITIES, INC.

UNDER CONTRACT NO. EY-76-C-02-0016 WITH THE

UNITED STATES DEPARTMENT OF ENERGY 


\section{DISCLAIMER}

This report was prepared as an account of work sponsored by an agency of the United States Government. Neither the United States Government nor any agency Thereof, nor any of their employees, makes any warranty, express or implied, or assumes any legal liability or responsibility for the accuracy, completeness, or usefulness of any information, apparatus, product, or process disclosed, or represents that its use would not infringe privately owned rights. Reference herein to any specific commercial product, process, or service by trade name, trademark, manufacturer, or otherwise does not necessarily constitute or imply its endorsement, recommendation, or favoring by the United States Government or any agency thereof. The views and opinions of authors expressed herein do not necessarily state or reflect those of the United States Government or any agency thereof. 


\section{DISCLAIMER}

Portions of this document may be illegible in electronic image products. Images are produced from the best available original document. 
BNL 50822

UC-13

(General, Miscellaneous, and Progress

Reports (Nonnuclear) - TID-4500)

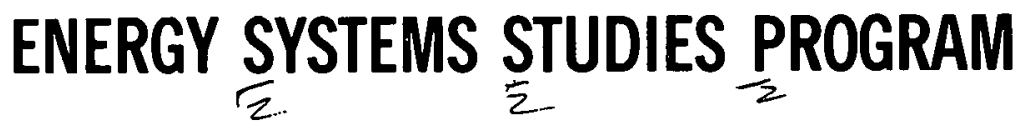

\author{
ANNUAL REPORT \\ FISCAL YEAR 1977
}

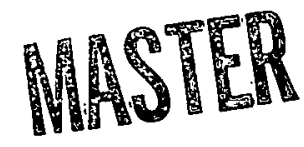

\author{
M. Beller, Editor
}

Contributors
H. Abilock
A. Hermelee
D.J. Behling, Jr.
L.L. Juang
M. Beller
A.S. Kydes
N. Bhagat
J. Lukachinski
G. Boyce
P. Newhouse
E.A. Cherniavsky
J. Rabinowitz
J. Congemi
M. Reckard
J. Davidoff
A.W. Reisman
A. Doernberg .
Y. Sanborn
V.K. Donaldson
J. Schank
R. Goettle
W.A. Sevian
G. Goldstein
J. Smith
P. Groncki
R.G. Tessmer
D. Gunwaldsen

\section{JANUARY 1978}

This report was prepared as an account of work sponsored by the United States Government. Neither the United States nor the United Government. Neither the Energy, nor any of their employess Department of contractors, subcontreir employees, nor any of their any warrenty, express ors, or their employees, makes hability or responsibility for the ar assumes any legal or ucefulness of any infor the accuracy, completeness prosess diss of any information, apparatus, product or infringe privately or represents that its use would not

\section{Prepared for the \\ UNITED STATES DEPARTMENT OF ENERGY \\ by the \\ NATIONAL CENTER FOR ANALYSIS OF ENERGY SYSTEMS}

\author{
BROOKHAVEN NATIONAL LABORATORY \\ UPTON, NEW YORK 11973
}


NOT I C E

This report was prepared as an account of work sponsored by the United States Government. Neither the United States nor the United States Department of Energy (DOE), nor any of their employees, nor any of their contractors, subcontractors, or their employees, makes any warranty, express or implied, or assumes any legal liability or responsibility for the accuracy, completeness or usefulness of any information, apparatus, product or process disclosed, or represents that its use would not infringe privately owned rights.

Printed in the United States of America Available from

National Technical Information Service

U.S. Department of Commerce

5285 Port Royal Road

Springfield, VA 22161

Price: Printed Copy $\$ 6.00$; Microfiche $\$ 3.00$

May 1978

800 copies 


\section{ABSTRACT}

This report summarizes the Energy Systems Studies Program carried out for the Department of Energy (DOE) in FY 1977. It includes the work done by the Energy Modeling and Data Group, Technology Assessment Group, and Economic Analysis Division in support of DOE programs, and briefly describes the scope of work planned for FY 1978. 


\section{ACKNOWLEDGEMENTS}

The contributions of Rita Kito, Grace Schwaner, Donna Visone, and Mary Lou Weis in editing, typing, and coordinating the assembly of this document are gratefully acknowledged. 
ACKNOWLEDGEMEN'T.......................

Page No.

iii

iv

viii

LIST OF TABLES.

LIST OF FIGURES.

ix

1.0 INTRODUCTION....................... 1

2.0 PROGRESS DURING FY $1977 \ldots \ldots \ldots \ldots \ldots \ldots \ldots \ldots \ldots$

2.1 Energy System Model Development........... 14

2.1.1 Brookhaven Energy System Optimization Model............... 14

2.1.2 Coordination of National

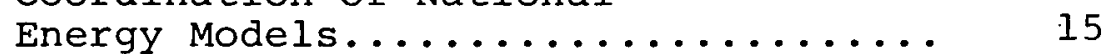

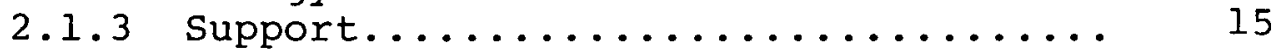

2.1.4 Time-Stepped Version of BESOM (TESOM) .................... 17

2.1.5 The Multi-Regional Energy Model...... 19

2.1.5.1 Formulation.............. 19

2.1.5.2 Model Development and status................ 22

2.1.5.3 Future Applications and Extensions........... 24

2.2 Technology Assessment

2.2.1 Interfuel substitution studies......

2.2.1.1 Conservation Study.........

2.2.1.2 Coal Study...............

2.2 .2 Technology studies.............. 28

2.2.2.1 New Technologies.......... 28

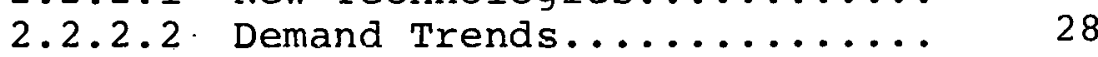

2.2.2.3 Reference Energy

2.2.2.4 Multi-objective

Analysis.............. 34

2.2.3 Trans-National Comparisons......... 40

2.2.4 Reference Materials system......... 48

2.2.5 Special Studies and

Assistance................... 49

2.2.6 Decentralized Enery Systems......... 51 
TABLE OF CONTENTS (Cont'd)

Page No.

2.3 Economic Analysis................. 57

2.3.1 Model Development............. 57

2.3.1.1 Extension of BNL Static

2.3.1.2 Coupling of BNL and

DRI Models............. 57

2.3.2 Data Estimation................. 59

2.3.3 Model Applications.............. 59.

2.3.3.1 Development of ERDA

Energy Projections.......... 59

2.3.3.2 Economic Analysis, Third

ERDA RD\&D Plan........... 59

2.3.3.3 Special Studies........... 60

2.4 Energy Model Data Base.............. 64

2.4.1 Data Base Development............ 64

2.4 .2 Model Development....................... 64

2.4 .3 Analytical Support.............. 64

2.4 .4 User Assistance...............6. 67

3.0 PROGRAM PLAN FOR FY $1978 \ldots \ldots \ldots \ldots \ldots \ldots \ldots \ldots \ldots 6 . \ldots \ldots$

3.1 Energy Models.................... 68

3.1 .1 System Optimization Models .............. 68

3.1 .2 Support.

3.1 .3 Regional Energy Model ............. 68

3.1 .4 Time stepped Version of BESOM......... 68

3.2 Technology Assessment. ................. 69

3.2.1 Interfuel Substitution studies......... 69

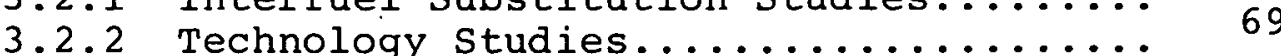

3.2.3 Introduction Rates of $\ldots \ldots \ldots \ldots 69$

3.2 .4 Trans-National Comparisons................... 69

3.2.5 Reference Materials Model............ 69

3.2.6 Special Studies and Assistance......... 70

3.2.7 Decentralized Energy Systems......... 70 
TABLE OF CONTENTS (Cont'd)

Page No.

3.3 Economic Analysis................. 71

3.3.1 Model Development............... 71

3.3.1.1 Extension of Input-Output

Model into an Interindustry

Linear Programming Model......

3.3.1.2 Development of an Input Output Pricing and Employment Model..............

3.3.1.3 Extension of the Time Frame and the Non-Energy Sectoral Detail of the HJA LTIM MODEL..

3.3 .1 .4 Coupling and Integrating Current BNL and HJA Models....

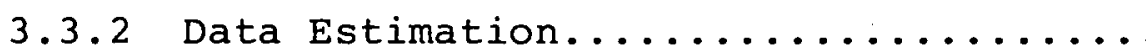

3.3.2.1 Estimation of Alternative Process Input Requirements....

3.3.2.2 Labor and Capital

Coefficients...............

3.3.3 Applications..................

3.3.3.1 Development of Energy

Projections............. 74

3.3 .3 .2 Social Welfare Analysis...... 74

3.3.3.3 Other DOE Support.......... 74

3.4 Energy Model Data Base............. 75

3.4.1 Date Base Development............ 75

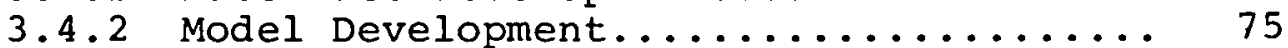

3.4 .3 Analytical Support............. 75

3.4 .4 User Assistance.............. 75

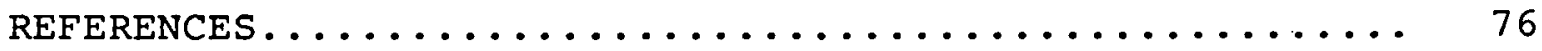

APPENDIX A - Industrial Process Modeling........... 78

APPENDIX B - Multi-Regional Model............. 84 
LIST OF TABLES

Table No.

1

2

3

4

5

6
Title

Regional Structure for Multi-Regional

Page No.

20

Functional Energy Services

(End-Use Demands)

21

Multi-Objective Analysis Results (1985)

Individual Minimization Results - Values

41

Multi-Objective Analysis Results (2000)

Individual Minimization Results - Values

42

Comparison of Multi-Objective Analysis

Results (1985) Approach \#1 and "Best Case"

Results (1985)

43

Comparison of Multi-objective Analysis

Results (2000) Approach \#l and "Best Case"

Results

44

- viii - 
Figure No.

1

2

3

4

5

6

$A-1$
Title

Page No.

Coal Supply and Demands

Regions and Centroids

Power Costs Under Existing and Proposed

Environmental Regulations

Sectoral Energy Differentials, Japan-United States

Integrated BNL/DRI Model for Long Term Energy/Economic/Environmental Analysis

National Energy System Network for ESS Model

Cement Manufacturing Process 


\subsection{INTRODUCTION}

This is the fifth annual progress report of the Energy systems Studies Program, supported at Brookhaven National Laboratory by the office of the Assistant Administrator for Planning, Analysis and Evaluation in the Energy Research and Development Administration (ERDA), which has been merged into the newly formed Department of Energy (DOE). The intention of this report is to briefly summarize major activities and objectives of the program during Fiscal Year 1977. Complete results of this work are described more fully in topical reports issued at appropriate stages in the course of the program.

This program is carried out in close coordination with other activities in the National Center for Analysis of Energy Systems (NCAES), which is organized within the Department of Energy and Environment at Brookhaven. The Center contains working groups in the following areas with specific responsibilities:

1. Policy Analysis

2. Economic Analysis

3. Biomedical and Environmental Assessment

4. Technology Assessment

5. Energy Data and Models

Each of these working groups draws on the collective skills and capabilities of the staff including chemical, electrical, and mechanical engineers, physicists, chemists, physicians, ecologists, epidemiologists, economists, applied mathematicians, and computer specialists. The staff has long-term experience in energy research and development. Many consultants from industry and the academic community are engaged on a continuing basis and contribute to the program as the need arises.

The Biomedical and Environmental Assessment Division, a joint program between the Medical Department and the Department of Energy and Environment, is affiliated with the Center.

The programs now included in the Center have provided analysis and support for ERDA, the National Science Foundation office of Energy R\&D Policy, the office of Science and Technology, and 
the Council on Environmental Quality. Collaborative work is in progress with the Federal Energy Administration (now part of DOE) and other Federal and state agencies.

Specific objectives of the National Center for the Analysis of Energy systems are:

1. to perform energy technology assessments on a continuous basis to support ERDA planning and budget allocation;

2. to perform special regional and national policy studies in support of ERDA objectives;

3. to explore international aspects of energy in relation to technology and policy;

4. to develop improved data bases and analytical methods for use in energy policy analysis and technology assessment;

5. to provide a central focal point for the coordination and integration of energy data and models through collaborative efforts with universities and industry;

6. to maintain current information on the technical, economic, and environmental characteristics of energy technologies for use by ERDA and other agencies engaged in energy technology assessment;

7. to cooperate with and assist other Federal agencies, regional planning and regulatory agencies, universities, and industry groups in the analysis of special problems of mutual interest and in the dissemination of information and analytical methods; and

8. to provide a site and support facilities for workshops and special task groups assembled to address important topics.

The progress report covers only part of the overall effort carried out in the National Center at BNL, and describes activities which were performed in support of Planning, Analysis and Evaluation programs within ERDA. Therefore, the areas discussed are Energy Models and Data, Technology Assessment, and Economic Analysis. 
The Fiscal Year 1977 highlights for these activities include the following:

1. Support of ERDA in development of energy forecasts.

2. Development of a Reference Energy System format which incorporates greater technological detail, emphasizing decentralized energy systems.

3. Completion of a study of energy use in Japan vis-a-vis the United States.

4. Completion of a study of potential coal use in the 19852000 time frame.

5. Completion of a conservation study analyzing specific options in various consuming sectors.

6. Development of a time-stepped version of the Brookhaven Energy System Optimization Model (BESOM).

7. Development of a multi-regional linear programming model based on BESOM.

8. Design and implementation of matrix and report generation capability for various models in PDS/MaGen.

9. Publication of a study analyzing an ERDA forecast case using multi-objective function techniques.

10. Completion of integration of BESOM with Data Resources, Inc., (DRI) Long Term Interindustry Transactions Model (LITM).

11. Application of input-output to disaggregated LITMdetermined aggregate projections.

12. Use of linked models for ERDA forecasts and analysis.

13. Linkage of Dynamic Energy System Optimization Model (DESOM) to LITM.

14. Application of DESOM/LITM to analyze long-term implications of a nuclear phaseout.

15. Combination of Input-Output (I-O) Model with BESOM to yield a single linear programming problem.

16. Estimation of relative prices for all 110 sectors of the I-O Model. 
17. Addition of new technology data on nuclear, coal gasification, solar, geothermal, solid waste, oil shale, fluidized bed combustion, solvent refined coal and coal liquefaction to the Energy Model Data Base (EMDB).

18. Update of the Energy Systems Network Simulator (ESNS) to include new technology and CONAES subcommittee nuclear data; use of these data in the Routine Emissions and Impacts Subgroup report for the CONAES study.

19. Completion of the ESNS/IRATE activity level model.

20. Development of an interactive activity level model aggregated to the level of a Reference Energy system (Energy System Simulator, ESS).

21. Addition of toxic trace element data to the EMDB.

22. Installation at BNL of the NEDS/REPS system developed by Booz, Allen and Hamilton for EPA and application of it in two basic studies.

For these analyses, a series of general planning tools which covers the entire energy system is utilized. Technology Assessment activities employ the Reference Energy System (RES) and Brookhaven Energy System Optimization Model (BESOM) as the primary analytical tools and consider both electric and non-electric energy forms. These models are updated during the course of the program to reflect the most recent data and also contain the flexibility required to permit the needs of each planning task to be addressed. Economic models, such as input-output and a dynamic optimization model, are also available to the program, as are combined models which provide the necessary interface between energy and the economy in the United States.

The activity in the Technology Assessment area is intended to provide a continuous assessment of the state of development and likely impact of new energy technologies and to perform studies of interfuel substitution. The scope of the assessments includes technologies and processes for all fuels and energy 
forms and all activities from extraction to end use as indicated on a Reference Energy System (RES). The RES indicates reference or existing technologies with which new technologies must compete. Impacts of new energy technologies are measured against Reference Energy Systems that project the technical structure of the energy system along with costs and environmental impacts through the year 2020. A unique feature of the methodology is the inclusion of the load structure of specific electrical demands and the incorporation of end-use technologies (airconditioners, combustion devices, engines, etc.) at the same level of detail as energy supply technologies, which are frequently a limiting factor in the rate of implementation of alternative energy systems and in energy conservation.

Future scenarios of the implementation of groups of technologies and new resources are developed. The socio-economic and environmental consequences are analyzed in detail and impact analyses are performed.

Comprehensive energy planning and analysis requires detailed study of the economic characteristics of energy technologies and of the relationship of energy to the social and economic structure of the nation. The objective of the Economic Analysis activity is to analyze these relationships ensuring that the technological realities of the energy system are reflected in economic modeling and analysis. Support is provided to the Technology Assessment work in economic analyses used for projections of energy demand and in the analysis of the economics of new technologies.

The Energy Data and Models activity provides a central capability to coordinate and integrate energy data bases and analytical modeling. Close coordination is maintained with university and industry groups developing data and models of interest to ERDA.

A comprehensive data base, the Energy Model Data Base (EMDB), is maintained at Brookhaven. This data base was developed under the auspices of the Council on Environmental Quality, Energy 
Research and Development Administration, National Science Foundation, and Environmental Protection Agency. The EMDB is available to governmental, industry, and university groups. The dissemination of the data on energy technologies that are contained in the EMDB provides a uniform and consistent basis for energy policy studies performed by these diverse groups. It also ensures that differences in policy recommendations may be attributed to the viewpoint of the group and not to differences in supporting data obtained from the data base. The Data and Models activity also supports the studies performed within the center at Brookhaven.

Included in the EMDB are:

- technical efficiencies and fuel requirements of 400 energy supply processes and 200 end uses;

- emissions (air and water), occupational hazards, waste, and costs of individual processes and end uses; and

- labor, material, and water requirements of supply processes.

Individual data elements (efficiencies, emissions, cost) may be extracted from the data base for each process. This information may be aggregated to provide a summation of elements associated with a given energy trajectory (e.g., coal to iron and steel production), a subsystem (e.g., all uses of coal), or the complete Reference Energy system as projected for some future planning period.

The modeling responsibility includes coordination and integration of energy data and models useful to DOE, as well as maintenance and development of the energy system models used in the energy programs at Brookhaven.

While the models that are available to the program are unique and play a major role in the planning tasks, the scope of the tasks is not limited to that which can be accomodated in the models. In addition to the capability within the group directly involved in this program activity, a wide range of technical, economic, biological, medical, and general environmental expertise 
is available at Brookhaven that may be drawn upon as required for specific planning tasks. The energy and environmental studies at Brookhaven have been interdisciplinary in nature and close interdepartmental working relationships have been established. In addition, a close working relationship is maintained with personnel in the Urban and Policy Sciences Department at the State University of New York at Stony Brook.

There is an increasing interest in the energy systems analysis capabilities at Brookhaven among industrial groups and several discussions and informal cooperative ties have been established.

In addition to the studies performed in support of Planning and Analysis activities, a series of regional studies lend an additional dimension to technology and policy analysis. The Policy Analysis Division of NCAES, supported by the Division of Biomedical and Environmental Research, carries out studies examining the implications of alternative energy futures on a regional basis, with particular emphasis on the Northeast. This study focuses on social, economic, and environmental impacts for this region, thus providing a significant contribution to national energy planning in collaboration with related programs at the DOE laboratories which are structured to similarly analyze other regions of the U. S.

Support is also provided to the office of International Affairs of DOE. An International Energy Agency (IEA) Systems Analysis program was initiated to evaluate technologies of mutual interest to participating nations for the development of $R \& D$ agreements. Brookhaven and Juelich (West Germany) are the designated laboratories where participants carry out these studies. Another area of investigation involves analysis of policies and programs addressing the energy problems of Developing Countries, in support of Department of Energy and Agency for International Development. The National center also collaborates with the Commission of European Communities, working on an energy model for Europe, and was involved with the Workshop on Alternative Energy Strategies (WAES), performing analyses for the U. S. within the context of global energy trade. 


\subsection{PROGRESS DURING FY 1977}

The Energy Systems Studies Program is divided into four major areas:

1. Energy System Model Development

2. Energy-Economic Model Development

3. Technology Assessments and Support

4. Energy Model Data Base Activities

Brief summaries of these areas are provided below, with more detail furnished in following sections of this report.

1. Energy System Model Development

Brookhaven Energy System Optimization Model (BESOM)

The most important development was the reformulation of BESOM in PDS/MaGen. This change permits faster, more accurate data changes and increased reliability of model output.

Other model refinements included the addition of decentralized technologies, and environmental coefficients for some advanced technologies.

Time-Stepped Optimization Model (TESOM)

A time-stepped version of BESOM was developed as an alternative tool to provide optimal levels of decision variables based on those in the previous time-steps, and also based on the retirement rates of "old" capital stocks. It also incorporates "current" assumptions involving economic and technological factors. Multi-Regional Energy Model (RESOM)

A multi-regional linear programming model was developed as a single period representation of the U. S. energy system defined over nine Census regions. Regions are linked through the creation of national resource pools for coal, crude oil and natural gas. Balance equations for these pools allow the potential for foreign resource transfers. The model is currently being validated.

\section{Support}

Technical assistance was provided to Planning, Analysis and Evaluation in using BESOM in conjunction with the economic models 
for the ERDA forcast work, and also in subsequent analysis of the National Energy Plan (NEP).

2. Technology Assessment

Interfuel Substitution Studies

A conservation study analyzed the impact of specific conservation options in selected sectors of the energy system against a baseline case for the year 2000. The major finding of the study was that improved building standards in the residential and commercial sectors, and the use of cogeneration in industry are costeffective, and can result in an $11 \%$ drop in primary energy use.

A study of coal use was also completed in this period. Coal shipments from eight demand regions to nine supply regions were analyzed in terms of cost and environmental effects. A major conclusion was that low sulfur western coal would be heavily utilized under existing New Source Performance Standards, but the adoption of Best Available Control Technology (BACT) with 90\% sulfur removal would discourage western coal use and improve the prospects for nuclear power.

Technology Studies

Cognizance of the state of the art and important technical characteristics of technologies was maintained, and used in the course of energy forecast work to be described later in this report.

A study of multi-objective analysis of alternative objective functions to be used with BESOM was started, and is nearing completion. In addition to considering minimum cost as the objective function, reduced capital cost, imported oil, resource use and environmental impacts are also weighted into the analysis. Trans-National Comparisons

Comparisons of energy use among nations is useful for estimating improvements in energy options based upon the experience of others. A previous study comparing energy use in sweden with that in the U. S. was very instructive and a new study comparing the U. S. with Japan indicates that lower per capita consumption by the Japanese is mainly due, in the residential and commercial 
sectors, to lifestyle and cultural differences, rather than technological distinctions. The industrial sector of Japan is distinctively more efficient because of the more recent vintage of its capital stock. The transportation sector in Japan uses mass transit to an extent not found in the U. S. In summary, personal consumption of energy in Japan is inextricably linked to income levels and cultural factors.

Reference Materials Model

The Reference Materials Model is being used in a study to compare the net energy effects of solar heating and conservation from increased insulation using data developed previously for the model.

Decentralized Energy Systems

A study of "decentralized" energy systems, comprising technologies located at or near consumers, is nearing completion. This study examines such technologies as solar, biomass conversion, congeneration, fuel cells, etc., in terms of their resource and lifestyle impacts in the timeframe of 2000 and beyond. Special Studies and Assistance

An analysis of the National Energy Plan (NEP) was conducted, in coordination with the Economic Analysis Division and Energy Models Group. Economic and resource impacts were determined, and technological shifts were ascertained.

Prior to this analysis, effort was directed toward a series of forecasts developed by ERDA Planning, Analysis and Evaluation based upon several possible energy futures. These are more fully described in the section on Economic Analysis.

\section{Economic Analysis}

Model Development

Several improvements were made in extending the Brookhaven input-output economic models and in coupling the Brookhaven energy system and the economic input-output models to the Data Resources Inc. (DRI) inter-industry and economic growth models. This latter 
project was carried out jointly with DRI. Under subcontract to BNL, DRI also considerably improved and integrated their interindustry model and their growth model.

Data Estimation

Trends in gross labor productivity from 1967 to 2000 were estimated for each of the 110 sectors in the BNL I-O model. Applications

Combined energy-economic models were applied to four alterative energy/GNP projections in the 1985-2000 time period for ERDA forecasts. They were also used in analysis of the National Energy. Plan (NEP).

4. Energy Model Data Base (EMDB)

Improvements were made to the computer management of the EMDB through use of the newly acquired system 2000 data base management software package.

Addition of data on toxic trace element emissions resulting from energy supply and conversion processes was initiated. Model Development

Development continued on the Energy System Network Simulator (ESNS) and two offshoots: an activity level model, and an interactive version.

Analytical Support

Technical support was provided to the office of Environmental Analysis in the form of obtaining specialized output from the EMDB, making ESNS runs, training outside users of the EMDB and ESNS, and working with APAE/OEA contractors.

Two major studies were undertaken for OEA (in collaboration with outside contractors): an analysis of the National Energy Plan and the Montana Energy Study. User Assistance

Information on data and models and long-term support were provided to the International Energy Ágency systems analysis effort and the Committee on Nuclear and Alternative Energy Strategies study. Requests from users outside the NCAES for data and model descriptions were met. 
Following is a list of papers and publications by personnel engaged in these program efforts:

1. Bhagat, N., Ed., Reference Material Systems: A Sourcebook for Material Assessment, BNL 50609, December 1976.

2. Hoffman, K. C., Bhagat, N., Systems Approach to Materials Policy, Paper presented at 1976 IEEE Conference on Decision and Control, December 1-3, 1976.

3. Bhagat, N., Hoffman, K. C., Systems Framework for Materials Policy, BNL 21633, Paper presented at ASME Winter Annual Meeting, December 5, 1977.

4. Goettle, R. J., Cherniavsky, E. A., and Tessmer, R. G., An Integrated Multi-Regional Energy and Interindustry Model of the United States, BNL 22728, May 1977.

5. Hermelee, A. L., Regional Reference Energy Systems, EPRI EA-462, Prepared for the Electric Power Research Institute: 3412 Hillview Avenue, Palo Alto, California 94304, June 1977.

6. Doernberg, A., Energy Use in Japan and the United States, BNL 50713, August 1977 .

7. Hoffman, K. C., and Jorgenson, D. W., Economic and Technical Models for Evaluation of Energy Policy, Bell Jour. of Econ. 8 , 444,1977 .

8. Hoffman, K. C., and Jorgenson, D. (Harvard Univ.), TechnologicalEconomic Models for Strategic Planning, BNL 22867, Submitted for Special Session on Energy Systems Modeling, 7 th Triennial World Congress of the International Federation of Automatic Control, Helsinki, June 12-16, 1977.

9. Goldberg, Murrey D., Sevian, W., Reisman, A., Newhouse, P., Energy Model Data Base Program, BNL 21545, June 1976.

10. Nerhhouse, Paula H., Energy Data Base Application: Implementing the Energy Model Data Base Using System 2000, BNL 21854, September, 1976.

11. Hoffman, K. C., Mathematical Programming in Energy Modeling, BNL 21588, Presented at the ANS 1976 International Conference, Washington, D. C., November 15-19, 1976.

12. Hoffman, K. C., and Wood, D. O., Energy system Modeling and Forecasting, Annual Review of Energy, Volume 1, 1976.

13. Wright, B., Tax Policy and U. S. Petroleum Supply. Data Resources, Inc., January 1976. 
14. Hoffman, K. C., and Jorgenson, D. W., Economic and Technological Models for Evaluation of Energy Policy. Data Resources, Inc., June 1976.

15. Dullien, R., Ed., The DRI Long-term Interindustry Transactions Model: Theory and Use, Data Resources, Inc., October 1976.

16. Dullien, R., Ed., User's Manual for the DRI Long-term Interindustry Transactions Model, Data Resources, Inc., Sept. 1976.

17. Tessmer, R. G., and Behling, D. J., The Effects of Alternative Oil Stockpiling Programs on the U. S. Economy, 1976-1979, final results, Brookhaven National Laboratory Formal Report, BNL 50541, June 1976.

18. Behling, D. J., and Dullien, R., A Combined Linear Programming and Econometric Systems Analysis of the Relation Between Energy, Growth and the Economy, BNL 21281, Paper presented at Summer Computer Simulation Conf., July 1976.

19. Behling, D. J., A Dynamic Systems Analysis of the Relation Between Energy and the Economy, BNL 21667, Paper presented at IEEE Computer Society Meeting, washington, D. C., Sept. 1976.

20. Behling, D. J., The Impact of Alternative Nuclear Moratorium Legislation on the U. S. Economy, Brookhaven National Laboratory Formal Report, BNL 50604, December 1976.

21. Tessmer, R. G., Input-output Capital Coefficients for Energy Technologies, Brookhaven National Laboratory Report, BNL 50608, December 1976 . 


\subsection{ENERGY SYSTEM MODEL DEVELOPMENT}

\subsubsection{Brookhaven Energy System Optimization Model}

BESOM was maintained and enhanced to reflect most current information and to incorporate refinements required for analytical purposes.

Perhaps the most important development was the formulation of the model in PDS/MaGen. During the FY 1977, two software packages, Apex III and PDS/MaGen, were acquired. The former is a linear programming optimizer package; the latter is a matrix and report generator package. Emphasis was placed on facilitating quick, accurate data changes, resulting in enhanced reliability of model output. A report on the PDS/MaGen formulation is in progress. The report generator capability has been employed to create a series of needed formats, including information that can be directly transcribed to a reference energy system, detailed cost tables, and sectoral breakdown data.

Among refinements to the model were the addition of new technologies such as cogeneration, wind electric, wood heaters, bromass, and municipal solid waste. New environmental coefficients that became available were inserted for coal liquifaction, oil shale, geothermal electric, methanol from coal, and solar thermal electric. A number of equations was added to represent alternate objective functions (e.g., installed capital, oil imports) and minimum fuel usage levels. The latter were essential to the development of the time-stepped model. A paper relevant to this model was written and reviewed suggesting a methodology for modeling market penetration and retirement of devices.

Incorporation of detailed modes of industrial processes began with the disaggregation of the cement industry from the process heat category. A description of the mathematical formulation is given in Appendix $A$; this also serves as an example of the use of PDS/MaGen in model formulation. 


\subsubsection{Coordination of National Energy Models}

This task was to be performed under a separate program that was not initiated. NCAES personnel participated in the NAS-CONAES modeling group and in the EPRI-Stanford Energy Forum.

\subsubsection{Support}

Technical assistance was provided to Planning, Analysis, and Evaluation ( $A P A E$ ) with runs of BESOM being made upon request. Assistance was also provided to APAE indirectly through aid given to other groups performing APAE tasks. In connection with F-1, F-2, F-3, and F-4 ERDA forecasts, numerous runs were made, and a multiple objective function study was performed with the F-2 forecasts. A paper on this study has been published (BNL 50685). Also related. to the F-2 forecasts was a series of seven runs made with environmental effluent charges incorporated into the objective function. The results of these runs were analyzed for presentation at an Operations Research Society meeting.

A study was performed using linear supply and demand elasticity representations to compare AET-8 ${ }^{(1)}$ energy flows and costs with Sourcebook $(2)$ energy flows and costs. Since AET-8 costs were lower and energy consumption generally higher than in the Sourcebook, the objective was to determine if the elasticity representation simulated the change and if not, what revisions would be required. A report on this work is in progress.

Since one of the elasticity representations developed is a quadratic programming problem with linear constraints, and since some of the suggested approaches to multi-objective function analysis involve non-linear objective functions, some effort was devoted to investigating and acquiring non-linear optimization software. Three packages, all of which had been developed by uriversities, were obtained. After several months of experimentation, the Harwell suite of packages was abandoned due to problems encountered in converting the code to be compatible with the BNL system. MPOS, developed at Northwestern University, was found to be incapable of solving problems of sufficient size and interest 
in a reasonable amount of time. Finally, MINOS, developed at Stanford University by Dr. Michael Saunders, was installed and tested. The algorithm optimizes any differentiable function subject to linear constraints. MINOS was compared to APEX III by running it on linear programming problems. MINOS was found to be competitive with APEX III for problems such as BESOM having fewer than 300 constraints but 4-6 times slower for problems having approximately 800 constraints. For problems containing approximately 2000 constraints (DESOM), MINOS never converged while APEX III converged in less than three minutes. In addition, MINOS exhibited some instability for the 800 constraint problem. However, when APEX III was used in generate the optimal basis for input to MINOS, MINOS did recognize the proper solution. It is anticipated that the combination of APEX with MINOS will provide some facility for solving the non-linear continuous type problems with linear constraints. The non-linear portion of MINOS has been tested on small problems.

Using a regression approach, a study was performed to analyze possible correlations between different objective functions, such as total cost and oil imports.

The general form of the regression function assumed was:

$$
\begin{aligned}
\ln (E) & =A+a_{1} \ln (S)+a_{2} \ln (C)+a_{3} \ln (F)+a_{4} \ln (N)-b_{1} s-b_{2} c-b_{3} F \\
& -b_{4} N+d_{1} \ln (\ln (S))+d_{2} \ln \left(\ln (C)+d_{3} \ln (\ln (F))\right. \\
& +d_{4} \ln (\ln (N))
\end{aligned}
$$

where

$$
\begin{aligned}
& E=\text { Environmental Index } \\
& S=\text { Total Oil and Natural Gas } \\
& F=\text { Capital Cost with End Use Devices } \\
& \mathrm{N}=\text { Natural Gas }
\end{aligned}
$$

To capture correlations, parameterizations were performed, minimizing each objective while restricting the levels of $\mathrm{S}, \mathrm{F}, \mathrm{C}$, and $\mathrm{N}$. 
A regression was done on all four variables taken together. The $\mathrm{R}^{2}$ statistic showed that $92 \%$ of the variability of the Environmental Index is explained by these four variables in 1985 Case while the comparable figure for 2000 is $89 \%$.

BESOM was made available to the following institutions, by sending either an MPS file of the linear programming problem or the Fortran matrix and report generator.

1. International Institute for Applied Systems Analysis Laxenburg, Austria

2. Australian Atomic Energy Commission Nuclear Science and Technology Branch

3. Energy Office of Puerto Rico

4. General Electric Center for Energy Systems Analysis Washington, D. C.

5. Institute for Environmental studies University of Wisconsin Madison, Wisconsin

6. Stanford University Electronics Lab Stanford, California

7. Virginia Polytechnic Institute University Center for Energy Research "Lorendas Project"

8. University of Virginia Department of Environmental Sciences Charlottesville, Virginia

9. Korea Development Institute Cheong, Ryang Seoul, Korea

10. Energy Laboratory, MIT Cambridge, Massachusetts

11. Korea Atomic Energy Research Institute Cheong, Ryang Seoul., Korea

\subsubsection{Time-Stepped Version of BESOM (TESOM)}

The Time-stepped Energy System Optimization Model was conceived and developed to provide (a) an improved, automated, simulation capability and (b) an alternative decision-making tool. to assist in the study of the evolution of national energy supply/ demand distribution systems. TESOM can be classified as a "myopic" 
time-phases model in that the optimal levels of the decision variables for any time-step are determined entirely from (a) the optimal levels of the decision variables in the previous timesteps, (b) the assumptions on the retirement/deterioration rates and average lifetimes of "old" stock, with associated costs and (c) the "current" assumptions involving energy-related economic and technological factors, potentially including both short-term and long-term supply curves. No knowledge of the future is assumed.

Mathematically, the time-stepped model is formulated as a sequence of expanded linear programming problems, one for each time step, representing the national energy systems (BESOMs). The first time-step problem represented in this sequence should replicate a recent historical year. The solution derived from the first year, along with the assumptions on retirement rates, average lifetimes and costs of stock in-place at the end of the first timestep, are incorporated as additional constraints to be met in the next time-step. The procedure is repeated until the solutions to all the time-steps are determined.

Work on TESOM proceeded along three directions. The first involved the development of a preliminary FORTRAN version of TESOM which would demonstrate the viability and utility of the concept. The task involved the expansion of BESOM to include information regarding the carry-over of "old" stock and the writing of subroutines which would transfer the necessary data between timeperiods. This task has been completed and the model performance has been tested in special support work for APAE. Preliminary results to date underscore the viability and utility of TESOM as a useful tool to be added to the repertoire of energy systems models.

The second direction involved the development of an interactive program which prompts the decision-maker or energy analyst with a series of questions relating to the carryover of old stock. At the conclusion of the session, the program generates the appropriate control card sequence and submits the job for execution. 
This program has been debugged and used extensively.

The third direction involves the formulation and implementation of TESOM in PDS/MaGen. Formulation is complete, and implementation is anticipated in FY 1978. Some of the new features designed into the PDS/MaGen version of TESOM include: (1) an inventory of old stock (both supply capacity and end-use devices) carried over from previous time-steps (2) heat rates of central stations as a function of age, (3) operating and maintenance charges as a function of age, (4) time-dependent investment costs, (5) plant factors as a function of age, and (6) options to specify demand growth rates between time-steps.

2.1.5 The Multi-Regional Energy Model*

2.1.5.1 Formulation

The multi-regional linear programming energy model is a singleperiod representation of the nation's energy system defined over the nine Census regions of the United States (see Table I). For a given national specification, sensitivity analyses of the formulative demand, supply, cost, conversion efficiency, and environmental structures can be conducted. Such analyses provide information regarding the response of the national/regional optimal allocation and technology mix to changes in the model's exogenous parameters under a single decision criterion. Alternatively, multi-objective analyses can be performed. Here, the purpose is to establish tradeoff loci for the variety of considerations which enter policy assessments and comparisons. The flexibility afforded by the formulation of the multi-regional model permits the construction of a geographic hierarchy of multi-objective studies; national objective vs regional objective, region objective vs. regional objective.

*This activity was part of the continuing Energy systems studies and Regional Energy Studies Programs sponsored by, respectively, the Assistant Administrator for Planning, Analysis, and Evaluation and the Assistant Administrator for Environment and Safety, United states ERDA. 
Table 1

Regional Structure for Multi-Regional

Energy and Interindustry Models

Census Region

1. New England

2. Middle Atlantic

3. East North Central

4. West North Central

5. South Atlantic

6. East South Central

7. West South Central

8. Mountain

9. Pacific states

Conneticut, Maine, Massachusetts New Hampshire, Rhode Island, Vermont

New Jersey, New York, Pennsylvania

Illinois, Indiana, Michigan, Ohio Wisconsin

Iowa, Kansas, Minnesota, Missouri, Nebraska, North and South Dakota

Delaware, D. C., Florida, Georgia Maryland, North and South Carolina, Virginia, West Virginia

Alabama, Kentucky, Mississippi, Tennessee

Arkansas, Louisiana, Oklahoma, Texas

Arizona, Colorado, Idaho, Montana, Nevada, New Mexico, Utah, Wyoming

California, Oregon, Washington, Alaska, Hawaii 
Table 2

$$
\begin{gathered}
\text { Functional Energy Services }{ }^{1} \\
\text { (End-Use Demands) }
\end{gathered}
$$

\begin{tabular}{|c|c|}
\hline Number & Description \\
\hline 01 & Space Heat \\
\hline 02 & Water Heat \\
\hline 03 & Cooking \\
\hline 04 & Air Conditioning \\
\hline 05 & Appliances \& Lighting \\
\hline
\end{tabular}

\section{RESIDENTIAL}

COMMERCIAL

\begin{tabular}{c} 
Number \\
\hline 06 \\
07 \\
08 \\
09 \\
10
\end{tabular}

Description

Space Heat

Water Heat

Cooking \& Other Heat

Air Conditioning

Miscellaneous Electric

\section{INDUSTRIAL}

Number

11

12

13

14
Description

Ore Reduction

Feedstocks

Process Heat

Electric Drive

Petrochemicals

\begin{tabular}{|c|c|}
\hline Number & Description \\
\hline 15 & Automobile \\
\hline 16 & $\begin{array}{c}\text { Truck, Bus, Rail } \\
\text { and Transit }\end{array}$ \\
\hline 17 & Air and water \\
\hline
\end{tabular}

\section{TRANSPORTATION}

\footnotetext{
${ }^{1}$ In addition to these, central station pumped storage (See Table V and Figure $I$ ) is both a supply category (on-peak) and a demand category (off-peak) for the electricity IEF.
} 
The multi-regional energy model represents an extension of the Brookhaven Energy System Optimization Model (BESOM) (3) and the Reference Energy system ${ }^{(2)}$. The types of resources, intermediate energy forms (IEFs), resource to nonelectric IEF conversion technologies, electricity and co-product generation technologies, and functional energy demands contained in this formulation are the same as those currently in BESOM, with the exception of the end-use sector which is more detailed (see Table II). This should not be viewed as either limiting or exhausting the specific alternatives which could potentially be included. Rather, an exemplary foundation is provided upon which a more detailed multi-regional energy model may be structured.

A major difference between this model and BESOM is seen in the electrical sector formulation, which is described briefly in Appendix B. A complete and mathematical presentation of this model is contained in Reference 4 .

\subsubsection{Model Development and Status}

The above version of the multi-regional model is to evolve through several stages of development. Such a strategy expedites the generation of regional analytic capabilities and minimizes the data and formulation requirements at each stage. The initial stage, which has been completed, involved the use of BNL's static national model, BESOM (Fortran version). The BESOM 1985 cost and constraint structure were replicated and made region specific for the nine census regions of the United States. Regional resource supplies; conversion capacities, and energy demand data for the year 1972 were input to the demonstration model (5). Regions were linked through the creation of national resource pools for an aggregate coal type, a crude equivalent. petroleum resource, and natural gas. For a given resource, regions with excess supply could and had incentives to export to the national pool whereas regions with excess demand were forced to import from this pool at the national cost. Balance equations for each national pool were created and these included the potential for foreign resource transfers. The 
complete model was tightly constrained so as to reproduce the 1972 regional technology mix of energy supply, conversion, and demand described in Reference 5.

The subsequent phase of model development involved substantial modifications to the above effort. The model, now formulated using PDS/MaGen, contains a fully operative representation of the structure described in section 2.1.5.1. This includes:

1. An expanded set of end-use demand categories by sector;

2. The conceptual separation of the end-use electricity demands from the generation technologies which supply them;

3. The capability for potential interregional electricity transfers (of the continuous type);

4. The elimination of the national pool concept in favor of regional pools (for both resources and intermediate energy forms) with explicit region-to-region trade limits and transportation costs;

5. The incorporation of additional, "old" technologies for converting resources to IEFs (e.g., petroleum refineries, coal and gas processing plants);

6. The ability to fit the model with upward sloping supply curves for domestically produced energy resources;

7. Increased flexibility for future model expansions including (but not limited to) more detail in the nuclear fuel cycle, more varieties of coal and crude oil, the addition of alternative supply and demand technologies and product IEFs, and additional energy transportation options.

This second version of the model is currently being tested for the reference year, 1975. National and regional totals for coal, oil, gas, and electricity consumption or conversion by sector (residential, commercial, industrial, petroleum refining, utility, and transportation) were obtained from various sources $(6,7,8,9,10,11)$. Allocations to specific end-uses within any sector-IEF combination were developed according to the methodology established in Reference 5 and then controlled to the reported totals. The IEF-to-demand 
and fuel input variables of the 1975 validation run have been bounded to lie between $80 \%$ and $110 \%$ of these corresponding values. Regional resource supply curves for "typical" coal and crude oil aggregates and for natural gas were developed using 1975 production and regional average well-head or mine-mouth price data as the initial increments and the FEA-Pies model data for subsequent increments $(11,12)$. Regional trade flow limits and energy transportation costs were also developed from a variety of sources $(9,11,12,13)$. Other data including supplementary fuel charges (net of transportation costs), capital (including end-use devices) and O\&M costs, and conversion efficiencies were taken directly from the national model (BESOM) and replicated for the Census regions. The capital and $O \& M$ cost structures for existing generation, transmission, and distribution capacity in the electric sector are soon to be regionalized as the results of a regional cost analysis and cost estimating framework become available. * It is expected that the testing phase of development will be completed by the end of November, 1977 at which time policy analysis applications, model review activities, and data revision and structural modification efforts may be undertaken.

\subsubsection{Future Applications and Extensions}

The multi-regional energy model is to be initially used in the support of two broadly defined policy analysis programs ongoing at $\mathrm{BNL}^{* *}$. The first of these, the National Coal Utilization Assessment under the Regional Studies Program, concerns the implications of increased coal utilization in the United States. The multiregional model has been slated as the mechanism for an evaluation of the initial scenarios, the many policy alternatives affecting coal utilization (e.g. the impact of BACT, oil and gas use taxes),

\footnotetext{
*This activity was performed by Logistics Management Institute (LMI), Washington, D.C. as part of the Energy Policy Analysis Program sponsored by the Assistant Administrator for Environment and Safety U.S.ERDA. The results are currently being reviewed by investigators at both BNL and LMI.
}

**Both currently sponsored by the Assistant Administrator for Environment and Safety, U.S.ERDA. 
and certain transitional constraints and/or substitution limitations which have been developed or have subsequently emerged during the first year of this effort. Secondly, the Environmental Policy Analysis Program includes research efforts aimed at addressing the health and environmental implications associated with major fuel shifts (not limited to increased coal utilization and including conservation and/or decentralization strategies). Here, the multi-regional will serve an intermediate analytic function providing the basis for more detailed spatial health and environmental impact analyses and summarizing the energy cost and allocative implications of scenario variation's arising from such analyses. Extensions to the model occur in three major areas. First, the development on an integrated multi-regional energy and interindustry model of the U. S. (4) is to continue. Professor walter Isard (Cornell University and University of Pennsylvania) has already provided useful information in support of this activity. This includes region-to-region trade flow data for the selected general industries of the model and, more importantly, special studies of industrial location and regional trade patterns for the iron and steel, aluminum, and petrochemicals industries. Second, since the multi-regional energy model contains fairly detailed representations of regional electric sectors and since many of our policy analyses focus on them, it seems appropriate that a simpler and more flexible analytical tool be developed for special problems. Thus, a multi-regional econometric model of the electric sector has been proposed. The multi-regional energy model is to be parametrically run to generate "pseudo data" from which the econometric parameters are estimated (see Reference 14 for an example of this technique). The resulting econometric model represents a simple and, yet, powerful analytic structure for a wide range of policy questions for which technological detail is not a requirement. Further, the results of the pseudo data technique are intuitively appealing in that they represent an efficient way of characterizing the gross substitutions and trade-offs which occur in the highly detailed process model. Finally, efforts 
will continue to more fully integrate the multi-regional energy model with the national energy-economic models and the subregional energy-environmental models. (15) 


\subsection{TECHNOLOGY ASSESSMENT}

\subsubsection{Interfuel Substitution Studies}

\subsubsection{Conservation Study}

The Conservation Study contains an analysis of modifications to baseline energy demands previously developed at Brookhaven National Laboratory, described in the "Sourcebook for Energy Assessment". (2) The baseline energy demands for the year 2000 are modified by introducing successively three sets of energy conservation options. These are evaluated in light of (1) measurement of their fuel savings impact on the system, (2) implementation levels that are technically feasible, and (3) considerations of stocks turnover that limit rate of introduction.

The study is conceived as an application of the modeling and demand projection capability existing at Brookhaven to specific options in energy conservation. It is thus not to be viewed as a comprehensive evaluation of energy conservation potential. This concept is extremely complex and simple cost minimization-capital stock replacement models do not capture it in its entirety; "conservation" is closely linked not only to technology, but to prices, policy, and the mix of output in the economy. Within the narrower framework utilized in this body of the report the results yield: (1) cost effective implementation of improved standards of buildings and the use of cogeneration in industry resulting in an $11 \%$ drop in primary energy use; (2) that the impact of increased end-use device efficiencies in industry and transportation results in a further drop in primary energy of $8 \%$ and (3) that even further decreases in primary energy use of $17 \%$ are achieved through a downward revision of growth rates in level of services assumed in the baseline.

The bulk of the modeling and analysis was performed during FY 76 and is described in last year's Annual Report. The study was completed during FY 77 adding cases (2) and (3) above in which cost of improved technologies and stock turnover information (gathered in detail for case (1)) is omitted; however, a more complete picture of energy conservation emerges from these additional cases. 


\subsubsection{Coal Study}

A second study in the Interfuel Substitution Series involves an analysis of coal use in the year 2000. The study utilizes eight coal supply regions, considering energy contents and two levels of contained sulfur (high and low) to supply nine demand regions. Fig. I shows the supply and demand centroids chosen. Patterns of future coal movement are analyzed, and low and high levels of coalbased synthetic fuel production are considered. Effects on these patterns of present and potential future environmental constraints are also analyzed. The study concludes that under present New Source Performance Standards, western coal will be a major developed energy source, but stringent application of the Clean Air Act amendments specifying Best Available Control Technology will depress the prospects for western coal development and brighten the future for nuclear power. Regional effects of these two scenarios are shown in Fig. 2, which compares possible electrical generating costs for coal vs. nuclear power regionally under these conditions for 1985 and 2000 .

\subsubsection{Technology Studies}

\subsubsection{New Technologies}

A major function in the Technology Assessment area is maintaining cognizance of state-of-the-art of emerging technologies. Estimation of parameters such as capital cost, operating and maintenance costs, efficiencies, R\&D trends, projected levels of implementation and possible competitive costs of alternate fuels, are necessary for use in judgmental and modelling tasks for technological and policy analysis. This task is accomplished by assigning specific technology areas to individuals who are responsible for maintenance of expertise in their areas. This expertise has been used in developing ERDA forecast cases, and for analysis of the National Energy Plan during FY 1977.

2.2.2.2 Demand Trends

Future trends in demand have been projected for the years 1985, 1990, and 2000 for three basic scenarios encompassing a high 


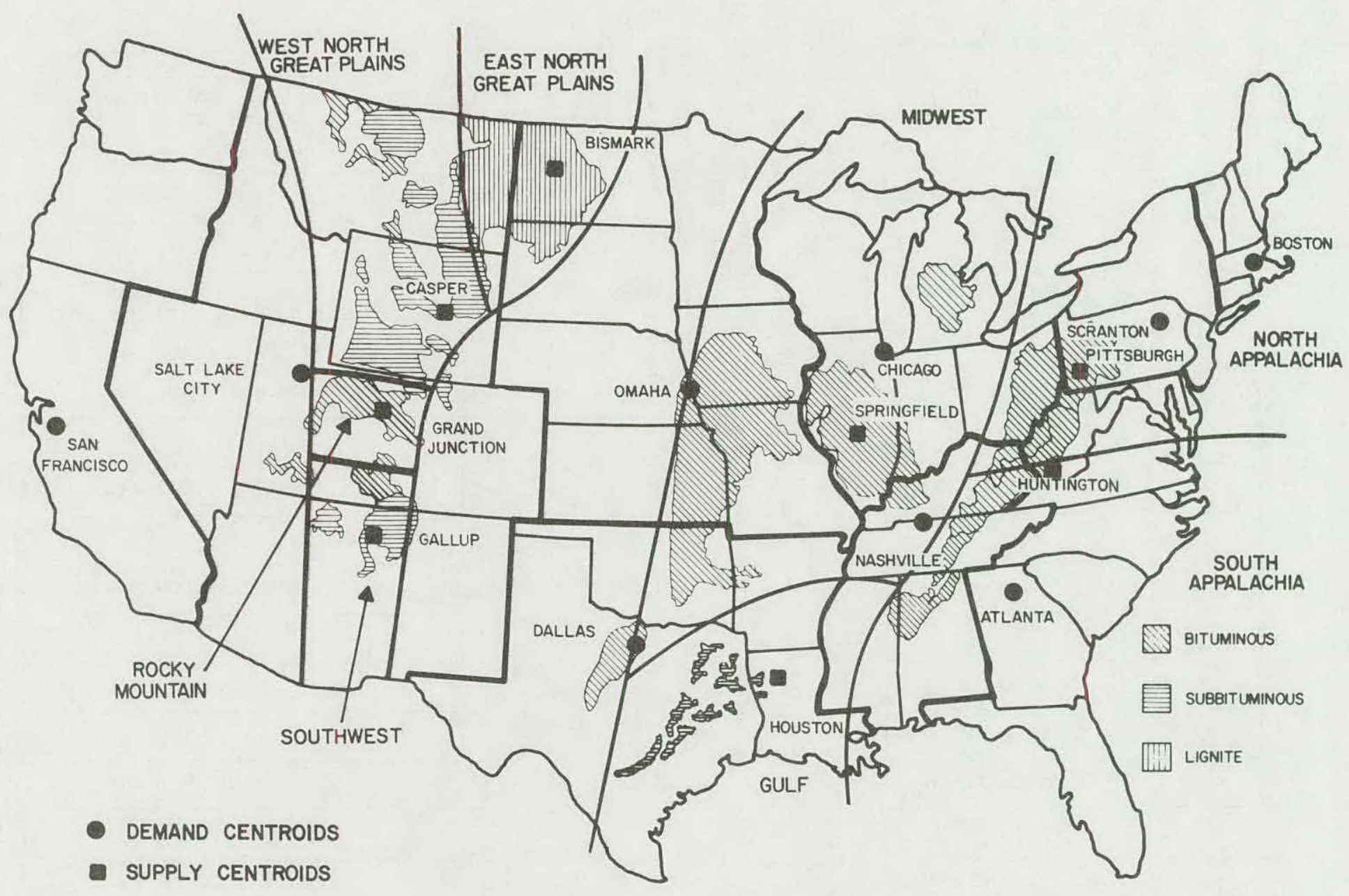

Figure 1. Coal Supply and Demands Regions and Centroids 

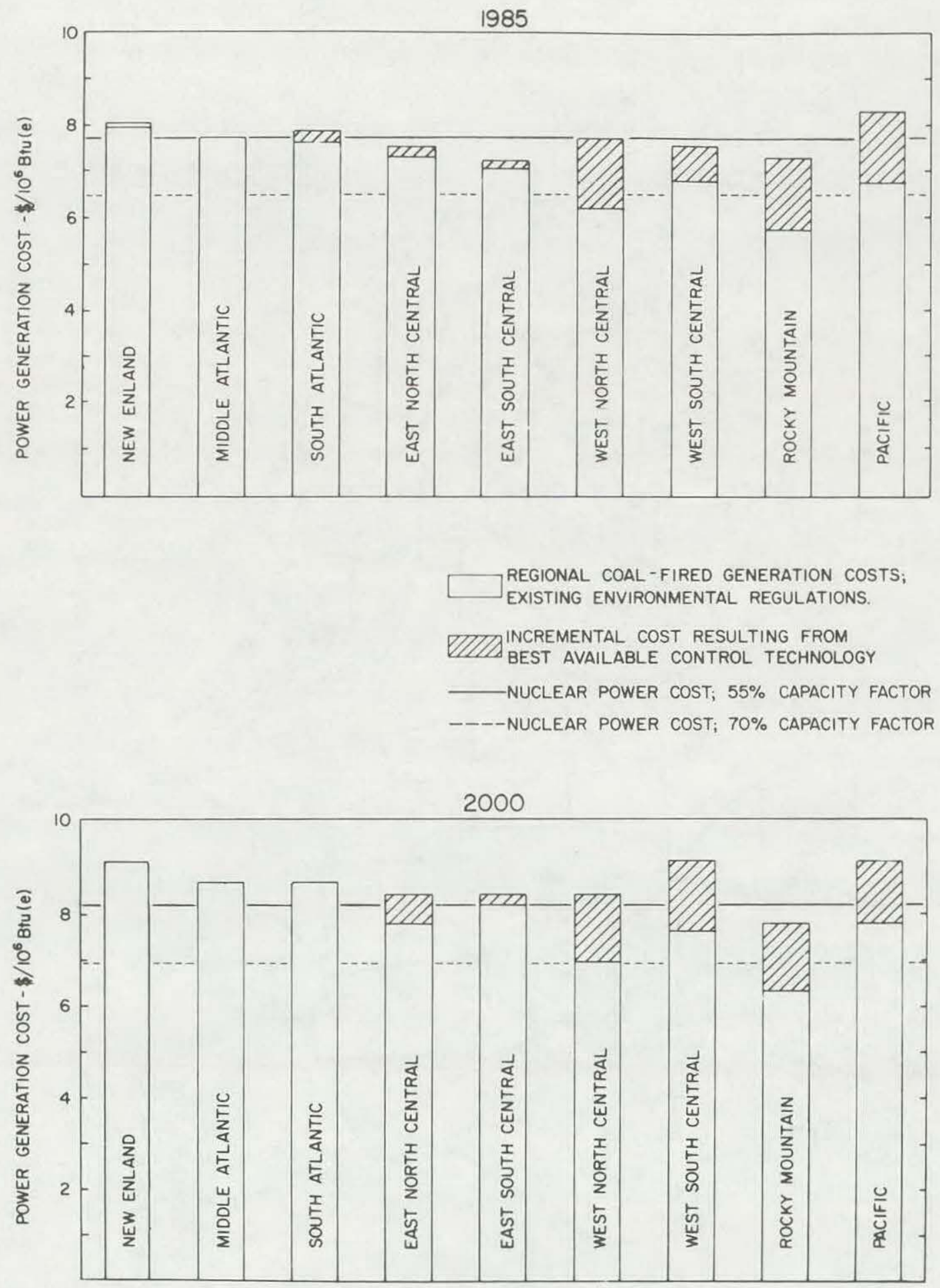

Figure 2. Comparison of Coal-Fired and Nuclear Power Costs Under Existing and Proposed Environmental Regulations 
price strong conservation case, a moderate price and moderate conservation case, and a high price case with no major improvements in technology. The results of these projections are being used in various energy and environmental systems studies. The Conservation Policy Project of the office of Environmental Policy is using the moderate price case as a basis in evaluating the health and environmental impact of not implementing the National Energy Plan. New technology implementation rates and final demand levels from the moderate price case have been used to determine the impact of not implementing the National Energy Plan as discussed in Section 2.2 .5 .

The basic premises of the high price strong conservation case, $(\mathrm{SF}-1)$, are:

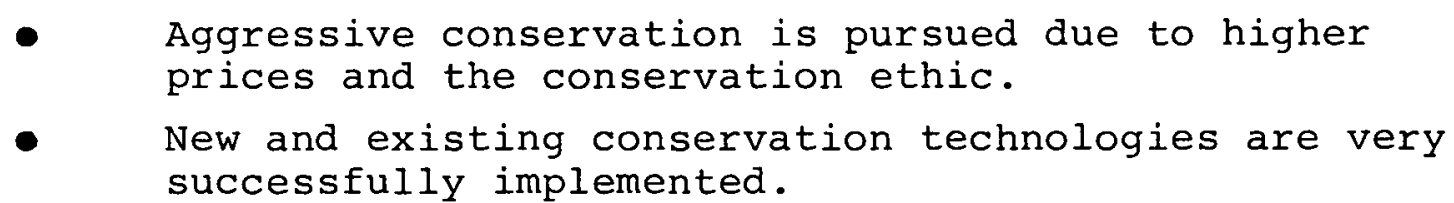

Total resource consumption increases from 93 quadrillion Btu's in 1985 to 117 quadrillion Btu's in the year 2000, with no significant lifestyle changes. The reduction in total resource consumption in 2000 from 139 quads in the moderate price case to 117 quads in SF-1 is due to (1) higher technical efficiencies which require less energy per unit of output, and (2) reduced demand for services cause of higher prices.

The basic premises of the moderate price and moderate conservation case, $(\mathrm{SF}-2)$, are:

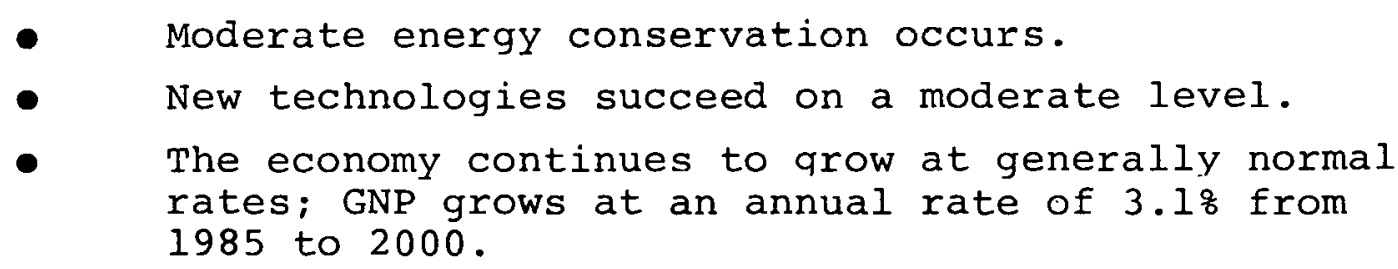

Total resource consumption increases from 98 quads in 1985 to 139 quads in the year 2000. Oil imports in 2000 rise to nearly 10 million barrels per day compared to 6 million barrels per day in SF-1. 
The basic premises of the high price case with no major improvements in technology, $(\mathrm{SF}-4)$, are:

- Price responsive demand reductions. No major improvements in technology.

Total resource consumption increases from 93 quads in 1985 to 117 quads in the year 2000. The reduction in resource consumption in 2000 from 139 quads in SF-2 to 117 quads in SF-4 is a result of reduced demand for services due to higher prices.

\subsubsection{Reference Energy System}

The Reference Energy System (RES) is a pictorial representation of the United States energy system in the form of a network that links resources to demand sectors through a series of technical conversions. During the years the RES has been in use, energy policy planning has undergone an evolution from a strict supply-oriented outlook to a more balanced view in which conservation and small scale conversion technologies are given condiderable attention. In response to this shift, during FY 1977, it was decided that the RES should add a group of "decentralized" technologies to the centralized systems already represented. The new design (Figure 3) features the following decentralized conversion devices: solar collectors, windmills, residential and commercial total energy systems, fuel cells, cogeneration of heat and power in industry, coke ovens, and low Btu coal gasification. Also added is district heat, which is a highly centralized but energy conserving technology.

The revised RES does not make the previous design obsolete, but simply allows a larger range of conversion systems to be explicitly represented. In addition, energy resources are now grouped into three uniquely distinct groups that are relevant to policymaking: nuclear, renewable (hydropower, geothermal, solar, and wood, wastes and biomass), and fossil resources (shale, oil, coal, and natural gas). 


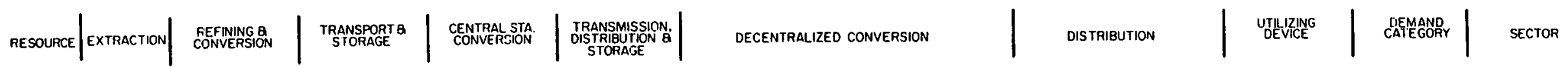

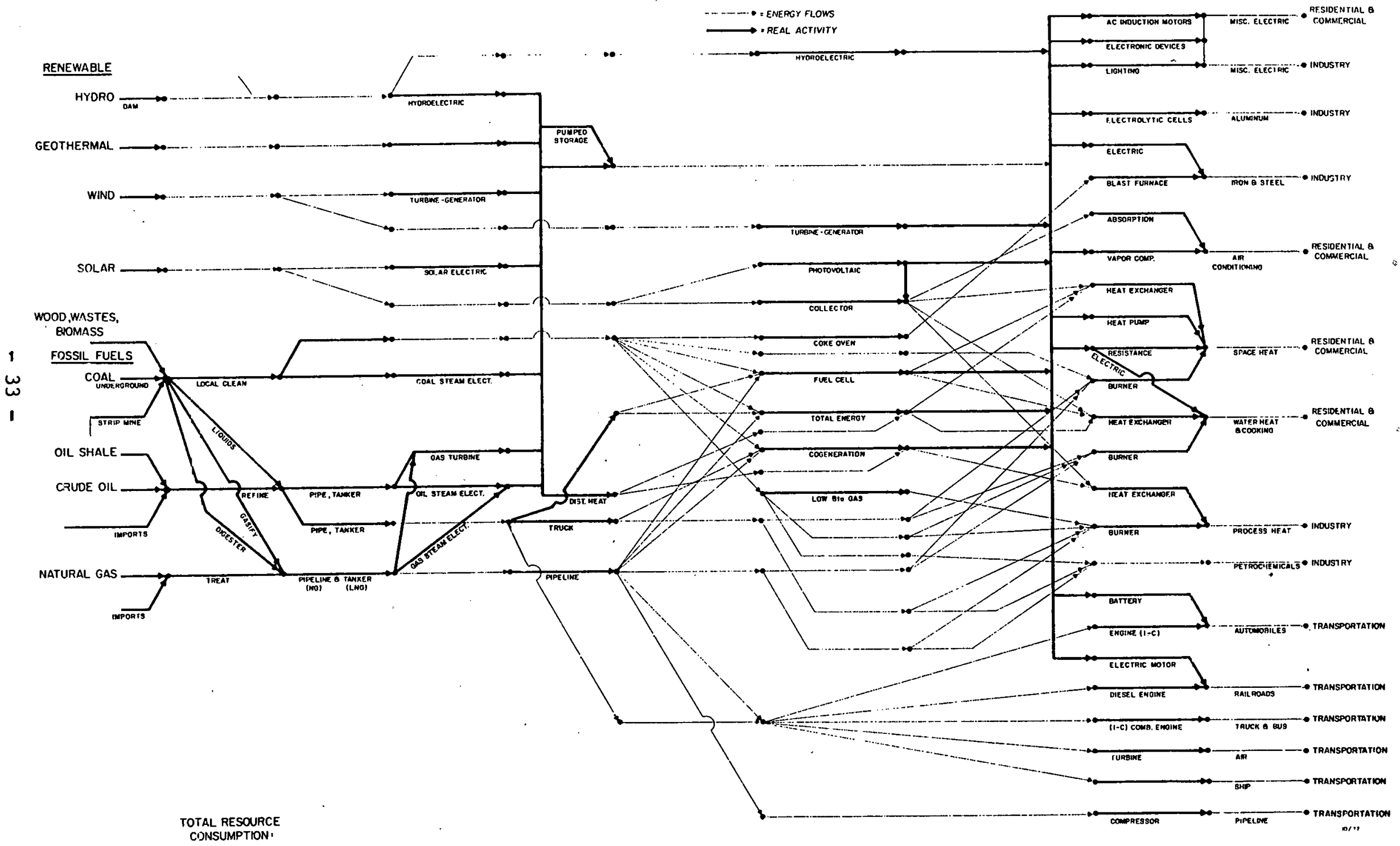

Figure 3. Reference Energy System 
Reference Energy System Modules

During FY 1977, work was begun on creating three detailed Reference Energy System-like diagrams for each of the main demand sectors. These are not yet fully operational, and only an example case was put together for the industrial sector using 1972 data. Their purpose is to give more detail in the end-use device area of the energy system; this level of detail would be inappropriate to include in a Reference Energy system, so separate modules are devised. The main thrust is to detail end-use device efficiency, for instance, show a separate efficiency for a burner and the shell of a house, or the engine combustion efficiency separate from friction and other losses in automobiles. The industrial sector example was put together from flow diagrams for specific industries and features separate flows for process steam and direct heat demands. A separation of these end-use demands by temperature regimes is possible but requires data that at present are incomplete. 2.2.2.4 Multi-Objective Analysis

The multi-objective analysis study's goal has been the development of an "automated" methodology for the analysis of BESOM-based (LP-based, in general) problems in which multiple competing objectives are to be "optimized". The procedure was to be "automated" in the sense of requiring fewer LP runs than the currently employed judgmental process (thereby increasing the speed of solution and reducing the user's burden of multiple computer runs and the assimilation of the resultant outputs) and providing a more structured basis for the decision-making activity. The candidate methodologies outlined below do not obviate the need for a decision-maker; as will be seen, the candidates require judgmental expertise also.

Professor Stanley zionts of the State University of New York at Buffalo, in conjunction with the Energy Models Group, has investigated the feasibility of applying an interactive programming method $(16)$ to the BESOM-based multi-objective analysis problem. This interactive method elicits the decision-maker's implicit utility function for the set of competing objectives. (The utility 
function is assumed to be linear; therefore, the mathematical formulation of the overall problem fits a linear format). The procedure starts with an arbitrary set of multipliers, and optimizes a composite linear objective function generated using these multipliers (i.e. $\Sigma_{i} \lambda_{i} O_{i}$ where the $\lambda_{i} s$ are the multipliers and the $O_{i} s$ are the competing objectives) to produce an efficient or Pareto-optimal solution to the problem. (Within an efficient solution, it is not possible to improve one objective without worsening at least one other objective.) For such a solution, the method finds a set of possible trade-offs (efficient vectors), each set being a feasible exchange. (An efficient vector represents a trade-off among objectives which results in another efficient solution). A number of such trade-offs is presented to the decisionmaker and he is requested to indicate whether each exchange is attractive to him or not. Then, a set of multipliers consistent. with his responses is constructed and the associated optimal solutions is found for that set of multipliers. The process is repeated by presenting new questions on trade-offs to the decisionmaker until convergence (i.e., no more attractive trade-offs) is reached.

The interactive program has been exercised by three independent decision-makers (two of the decision-makers were in-house staff; the third, a member of the ERDA staff). On the average, the meghod converged after five question sessions, with six to nine questions posed during each session. (Each session requires multiple LP runs).

In general, the decision-makers felt the interactive process showed promise and yielded results comparable to those obtained in the past by the judgmental process. However, it was observed that the decision-makers' responses (i.e., their implicit utility functions) usually depended not only on the actual trade-offs presented but also on the levels of the various competing objectives (i.e., their implicit utility functions were non-linear). 
A more general approach allowing for a concave non-linear utility function has been proposed. It is anticipated that the more general approach will be pursued in the coming fiscal year.

As background, a description of the current judgmental process follows. The procedure consists of essentially four steps. In Step 1 , the specific objectives to be analyzed are selected. Step 2 determines the unconstrained minimum for each of the target objectives. (The application of the interactive procedure described earlier also included the generation of the individual minima which were presented to the decision-makers as the "ideal" solution). During step 2, the behavior of all objectives is tracked as each one is minimized individually. A judgmental analysis of the observed behavior results in the identification of pairs of mutuallyopposed objectives. Step 3 involves a series of trade-off analyses, one per pair of objectives identified in step 2. Each pairwise analysis is accomplished by constraining one objective at various levels above its absolute minimum while minimizing the other. The results of step 3 are depicted by a set of pairwise trade-off curves. Step 4 develops the "best" combined case through a judgmental process based on the trade-off analyses. The process involves constraining a set of critical objectives (generally those identified as members of a competing pair in step 2) except one which is minimized. The constraint levels selected usually are obtained from the trade-off curves which normally exhibit a typical knee where small reductions in the constrained objective of the pair causes a slight increase in the other while further reduction causes a more significant rise.

The most recent application of the judgmental process is detailed within the report entitled Multi-objective Function Analysis of ERDA Forecast-2, Year-2000 Scenario, (BNL 50685).

Three candidate "automated" methodologies have been identified to date. All three consist of three steps and have identical first and second steps. As in the judgmental procedure, Step 1 entails the selection of the specific objectives to be analyzed. Step 2 
determines the unconstrained minimum for each objective selected. Again, the behavior of all objectives is recorded throughout the series of individual minimizations. A judgmental analysis of the observed behavior yields a set of objectives which exhibit significant deviations from their absolute minima during the minimization of one or more of the other objectives.

First, some notation will be defined and then the final step for each of the three methodologies will be presented.

Let there be $N$ target objectives, $o_{i}, i=1, \ldots, N$

Let $x_{j}=$ level of activity $j$ (in BESOM)

$c_{i j}=$ unit cost in terms of objective $i$ of activity $j$ (therefore, $o_{i}=\sum_{j} c_{i j} x_{j}$ )

$v_{i j}=$ value of $i^{\text {th }}$ objective in the optimal solution for the absolute minimization of the $j^{\text {th }}$ objective

$\operatorname{Min}_{i}=$ absolute minimum of $i^{\text {th }}$ objective (note: $\operatorname{Min}_{i}=\operatorname{Min}_{j} \mathrm{~V}_{i j}=\mathrm{V}_{i i}$ )

$I=$ set of indices of the objectives identified in step 2

$\operatorname{Max}_{i}=$ largest value of $i^{\text {th }}$ objective which occurred during the minimization of any of the objectives identified in step 2

$$
\left(\operatorname{Max}_{i}=\underset{j \varepsilon I}{\left.\operatorname{Max} V_{i j}\right)}\right.
$$

$\mathrm{Ax} \frac{\leq}{>} \mathrm{b}$ represent the standard BESOM constraint matrix 
Approach \#1

Step 3. Solve the following problem:

$$
\begin{aligned}
& \min \max _{i}\left\{\alpha_{i}\left(O_{i}-\operatorname{Min}_{i}\right), \forall i \varepsilon I\right\} \\
& A x \frac{\leq}{>} \mathrm{b} \\
& \text { where } \quad \alpha_{i}=\frac{1}{\operatorname{Max}_{i}{ }^{-M_{i n}}} \text { (ide., minimize the } \\
& \text { maximum inspan devil- } \\
& \text { timon, where the span } \\
& \text { for the th objective } \\
& \text { equals } \operatorname{Max}_{i}-\operatorname{Min}_{i} \text { ) } \\
& \alpha_{i}=\frac{1}{\operatorname{Min}_{i}}
\end{aligned}
$$

The above problem can be formulated as a LP as follows:

$$
\begin{aligned}
& \min z \\
& \operatorname{Ax} \leq \frac{}{>} b \\
& \alpha_{i}\left(O_{i}-\operatorname{Min}_{i}\right) \leq z \forall i \varepsilon I
\end{aligned}
$$

Approach \#2

Step 3. Solve the following problem:

$$
\begin{gathered}
\min \sum_{i \in I}\left(\frac{O_{i}-M_{i n}}{\operatorname{Max}_{i}-M_{i n}}\right)^{2} \\
A x \leq b
\end{gathered}
$$

$-38-$ 
This quadratic objective function appears in a least-squares format. The function may be viewed in a different manner. Letting $\frac{\mathrm{O}_{i} \text { Min }_{i}}{\operatorname{Max}_{i} \text { Min }_{i}}$ represent a variable weighting factor which increases linearly with the deviation of the objective from its minimum and $\frac{1}{\operatorname{Max}_{i}-\text { Min }_{i}}$ be a normalization factor, the function represents a summation of variably-weighted normalized deviations.

Approach \#3

Step 3. Solve the following problem:

$$
\begin{gathered}
\text { Min } \Pi_{i \varepsilon I}\left(\frac{O i-M i n_{i}}{\operatorname{Max}_{i}-M_{i n_{i}}}+1\right) \\
\operatorname{Ax} \frac{\leq}{>} \mathrm{b}
\end{gathered}
$$

This formulation contains a nonlinear objective function which may exhibit nonlinearities much larger than those of the quadratic function of Approach, \#2.

Whereas the judgmental process requires the execution of multiple LPs during its third step, the candidate approaches 1-3 require the execution of 1 LP, 1 quadratic program (QP), and 1 nonlinear program (NLP), respectively. Approach \# 1 could be expanded to include a fourth step in which the user alters the "weighting factors" (i.e., the $\alpha_{i} s$ ) repeatedly until satisfied. This would be a less rigorous version of the step of the interactive method in which a set of multipliers consistent with all of the decisionmaker's previous responses is constructed.

Currently, only Approach \# 1 has been exercised. The testing of Approaches \# 2 and 3 was delayed by a search for implementable $\mathrm{QP}$ and NLP algorithims. The search has culminated in the implementation of a large-scale nonlinear programming system for problems with linear constraints known by the mnemonic MINOS ("a Modular In-core Nonlinear Optimization System"). Since the requisite tools are now available, the testing of Approaches \#2 and 3 will. be expedited in the immediate future and a final report will ensue. 
Approach \#l has also been utilized to produce a sensitivity analysis of ERDA's Forecast 2-Year 2000 Scenario under varying levels of solar and geothermal technology implementation. The results are contained within a preliminary report entitled solar and Geothermal Energy Utilization in SF2: A Sensitivity Analysis, Task 1 Report.

Approach \#1 was executed for two target years: 1985 and 2000 (ERDA's Forecast 2). For each year, the judgmental "best case" was determined first (in-house decision-makers not directly involved with this study were employed). Next, Approach \#l was applied to each year and the resultant outputs were compared to the benchmark "best cases". Tables 3 and 4 present the results of the individual minimizations for 1985 and 2000, respectively. Tables 5 and 6 present the "best case"-Approach \#I comparisons for 1985 and 2000, respectively. As can be seen from the tables, Approach \#l. results compare quite favorabley to the "best case" results. It should be noted that target year 1985 had a much more constrained scenario than that of 2000 which resulted in 1985 Approach \#l values being considerably closer to their respective "best case" values than those of 2000 .

\subsubsection{Trans-National Comparisons}

Energy Use in Japan and the United States

A comparative study of energy consumption in Japan and the United states was undertaken during FY 77 in much the same spirit as a Sweden-United States comparison done during FY 76, i.e., a search for unique technological features that help explain at least in part the energy per capita differential between the two countries. In the case of sweden there are technological differences (district heating, insulation); in the case of Japan for the most part there are not. Standard of living and to a lesser degree, cultural differences, have a large impact on the residential and transportation sectors.

Gross Domestic Product per capita in 1974 in Japan was 63\% of that of the United States and energy consumption per capita only $37 \%$ of United States consumption. By sectors, the latter ratio 
Table 3

\begin{tabular}{|c|c|c|c|c|c|c|}
\hline $\begin{array}{l}\text { Activity } \\
\text { Level }\end{array}$ & $\begin{array}{l}\text { Cotal Cost } \\
\text { W/EUD }\end{array}$ & $\begin{array}{l}\text { Total Cost } \\
\text { w/o EUD }\end{array}$ & $\begin{array}{l}\text { Capital } \\
\text { Cost } \\
\text { W/EUD }\end{array}$ & $\begin{array}{l}\text { Imported } \\
\text { Oil }\end{array}$ & $\begin{array}{c}\text { Environmental } \\
\text { Index }\end{array}$ & $\begin{array}{c}\text { Total } \\
\text { Resources }\end{array}$ \\
\hline $\begin{array}{l}\text { Total Cost } \\
\text { W/EUD }\end{array}$ & 524.33 & $\begin{array}{l}\cdot \\
527.89\end{array}$ & 524.66 & 532.89 & 533.82 & 536.32 \\
\hline $\begin{array}{l}\text { Total Cost } \\
\text { w/o EUD }\end{array}$ & $2 s 1.02$ & 289.99 & 291.17 & 295.19 & 295.84 & 298.42 \\
\hline $\begin{array}{l}\text { Capital Cost } \\
\text { w/EUD } \\
\left(10^{9} \$\right)\end{array}$ & $1,775.05$ & & $1,773.75$ & $1,867.08$ & $1,861.33$ & $1,883.78$ \\
\hline $\begin{array}{l}\text { Imported } \\
\text { Oil }\end{array}$ & 23.00 & 23.00 & 23.00 & 21.32 & 23.00 & 23.00 \\
\hline $\begin{array}{l}\text { Environmental } \\
\text { Index } \\
\quad \text { (dimensionless) }\end{array}$ & 510.78 & $495.46^{\circ}$ & 515.17 & ${ }^{+} 510.10$ & 490.13 & 494.98 \\
\hline $\begin{array}{l}\text { Total Resources } \\
\qquad\left(10^{15} \text { Btu }\right)\end{array}$ & 98.69 & 97.04 & 98.72 & 97.82 & 96.91 & 96.79 \\
\hline
\end{tabular}


Table 4

MULTI-OBJECTIVE ANALYSIS RESULTS (2000)

Individual Minimization Results - Values

\begin{tabular}{|c|c|c|c|c|c|c|}
\hline $\begin{array}{l}\text { Activity } \\
\text { Level }\end{array}$ & $\begin{array}{l}\text { otal Cost } \\
\text { w/o EUD }\end{array}$ & $\begin{array}{c}\text { Total Cost } \\
\text { w/EUD }\end{array}$ & $\begin{array}{l}\text { Capital } \\
\text { Cost } \\
\text { w/EUD }\end{array}$ & $\begin{array}{l}\text { Imported } \\
\text { Oil }\end{array}$ & $\begin{array}{l}\text { Environmental } \\
\text { Index }\end{array}$ & $\begin{array}{c}\text { Total } \\
\text { Resources }\end{array}$ \\
\hline $\begin{array}{l}\text { Total Cost } \\
\text { w/o EUD } \quad\left(10^{9} \$\right)\end{array}$ & 421.35 & 429.64 & 452.58 & 431.18 & 462.92 & 452.56 \\
\hline $\begin{array}{c}\text { Total Cost } \\
\text { w/EUD }\end{array}$ & 758.86 & 746.10 & 770.02 & 774.46 & 795.73 & 791.31 \\
\hline $\begin{array}{l}\text { Capital Cost } \\
\text { w/EUD }\end{array}$ & $3,005.39$ & $2,744.23$ & $2,612.82$ & $3,125.70$ & $2,957.35$ & $3,108.23$ \\
\hline $\begin{array}{l}\text { Impor ted } \\
\text { Oil } \\
\end{array}$ & 21.58 & 26.49 & 40.00 & 18.51 & 39.61 & 40.00 \\
\hline $\begin{array}{l}\text { Environmental } \\
\text { Index (dimensionless) }\end{array}$ & 548.53 & 554.35 & 610.72 & 536.87 & 392.87 & 555.23 \\
\hline $\begin{array}{l}\text { Total Resources } \\
\qquad\left(10^{15} \mathrm{Btu}\right)\end{array}$ & 132.14 & 133.47 & 134.24 & 133.71 & 132.49 & 129.41 \\
\hline
\end{tabular}


Table 5

COMPARISON OF MULTI-OBJECTIVE ANALYSIS RESULTS (1985) Approach \#1 and "Best Case" Results

\begin{tabular}{|c|c|c|c|c|c|c|c|c|c|}
\hline Objective & & Values & & 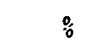 & e Min & & & Span & \\
\hline & $\begin{array}{l}\text { Best } \\
\text { Case }\end{array}$ & $\begin{array}{c}\text { Case } \\
\# 1\end{array}$ & $\begin{array}{c}\text { Case } \\
\# 2\end{array}$ & $\begin{array}{l}\text { Best } \\
\text { Case }\end{array}$ & $\begin{array}{c}\text { Case } \\
\# 1\end{array}$ & $\begin{array}{c}\text { Case } \\
\# 2\end{array}$ & $\begin{array}{l}\text { Best } \\
\text { Case }\end{array}$ & $\begin{array}{c}\text { Case } \\
\# 1\end{array}$ & $\begin{array}{c}\text { Case } \\
\# 2\end{array}$ \\
\hline $\begin{array}{l}\text { Total Cost } \\
\text { w/EUD }\end{array}$ & 538.68 & 534.99 & 535.08 & 2.7 & 2.0 & 2.1 & 119.7 & 88.9 & 89.7 \\
\hline $\begin{array}{l}\text { Total Cost } \\
\text { w/o EUD }\end{array}$ & 292.82 & 291.19 & 291.33 & 1.0 & 0.4 & 0.5 & 33.6 & 14.2 & 15.9 \\
\hline $\begin{array}{l}\text { Capita } 1 \text { Cost } \\
\text { w/EUD }\end{array}$ & $1,892.72$ & $1,845.36$ & $1,846.36$ & 6.7 & 4.0 & 4.1 & 108.1 & 65.1 & 66.0 \\
\hline $\begin{array}{l}\text { Imported } \\
\text { oil }\end{array}$ & 22.00 & 22.41 & 22.19 & 3.2 & 5.1 & 4.1 & 40.5 & 65.1 & 51.8 \\
\hline $\begin{array}{l}\text { Environ- } \\
\text { mental } \\
\text { Index }\end{array}$ & 500.12 & 506.43 & 510.19 & 2.0 & 3.3 & 4.1 & 39.9 & 65.1 & 80.1 \\
\hline $\begin{array}{l}\text { Total } \\
\text { Resources }\end{array}$ & 97.19 & 97.91 & 98.17 & 0.4 & 1.2 & 1.4 & 20.7 & 58.0 & 71.5 \\
\hline
\end{tabular}

Best Case: min Capital Cost w/EUD

Imported 0 il $<22.0$

Environmenta1 ${ }^{-}$Index $\leq 500.12$

Case \#1: $\min \max \{$ Capital Cost w/EUD, Imported 0i1, Environmental Index

Case \#2: min max $\{$ Capital Cost w/EUD, Imported Oil, Environmental Index

( $\$$ above minimum) 
Table 6

COMPARISON OF MULTI-OBJECTIVE ANALYSIS RESULTS (2000)

Approach \#1 and "Best Case" Results

\begin{tabular}{|c|c|c|c|c|c|c|c|c|c|c|c|c|c|}
\hline & Objectives & & & lues & & & \& $A$ & Mini & & & & & \\
\hline & & $\begin{array}{l}\text { Bcst } \\
\text { Case }\end{array}$ & $\begin{array}{c}\text { Case } \\
11\end{array}$ & $\begin{array}{c}\text { Case } \\
12\end{array}$ & $\begin{array}{c}\text { Casc } \\
13\end{array}$ & $\begin{array}{l}\text { Best } \\
\text { Case }\end{array}$ & $\begin{array}{c}\text { Case } \\
11\end{array}$ & $\begin{array}{c}\text { Case } \\
12\end{array}$ & $\begin{array}{c}\text { Case } \\
13\end{array}$ & $\begin{array}{l}\text { Best } \\
\text { Case }\end{array}$ & $\begin{array}{c}\text { Case } \\
1\end{array}$ & $\begin{array}{c}\text { Case } \\
12\end{array}$ & $\begin{array}{c}\text { Case } \\
13\end{array}$ \\
\hline & $\begin{array}{l}\text { Total Cost } \\
\text { w/o riun }\end{array}$ & 444.33 & 444.46 & 454.99 & 443.21 & 5.4 & 5.5 & 8.0 & 5.2 & 55.3 & 55.6 & 80.9 & 52.6 \\
\hline & $\begin{array}{l}\text { Total Cost } \\
\text { w/Eun }\end{array}$ & 783.40 & 764.00 & 795.34 & 763.56 & 5.0 & 2.4 & 6.6 & 2.3 & 75.2 & 36.1 & 99.2 & 35.2 \\
\hline & $\begin{array}{l}\text { Capital } \\
\text { Cost } \\
\text { w/FuD }\end{array}$ & $3,113.69$ & $2,820.27$ & $3,163.84$ & $2,831.84$ & 19.2 & 7.9 & 21.1 & 8.4 & 94.4 & 39.1 & 103.8 & 41.3 \\
\hline & $\begin{array}{l}\text { Imported } \\
\text { Oil }\end{array}$ & 22.00 & 26.91 & 22.41 & 26.15 & 18.9 & 45.4 & 21.1 & 41.3 & 16.2 & 39.1 & 18.1 & 35.6 \\
\hline & $\begin{array}{l}\text { Environ- } \\
\text { mental } \\
\text { Index }\end{array}$ & ८86.93 & 478.04 & 475.72 & 482.79 & 23.9 & 21.7 & 21.1 & 22.9 & 43.2 & 39.1 & 38.0 & 41.3 \\
\hline & $\begin{array}{l}\text { Total } \\
\text { Resources }\end{array}$ & $\|_{135.19}$ & 133.42 & 137.04 & 133.44 & 4.5 & 3.1 & 5.9 & 3.1 & 119.7 & 83.0 & 158.0 & 83.4 \\
\hline & & Best Case & $: \min$ & $\begin{array}{l}\text { vironment } \\
\text { nported } 0 i \\
\text { tal Cost }\end{array}$ & $\begin{array}{l}\text { a } 1 \text { Index } \\
1 \leq 22.0 \\
\text { w/EUn }\end{array}$ & 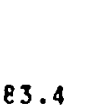 & & & & & & & \\
\hline
\end{tabular}

Case $1: \min \max$ |Total Cost w/EUD, Capital Costw/Fun, Imported 0ij, Environmental Index | (i span)

Case $2: \min \max \{$ Total Cost w/EUD, Capital Cost w/IUD, Imported Oil, Fnvironmenta1 Index\} (\& above minimum)

Case $3: \min \max \{$ Total Cost w/EUn, Capital Cost w/FUn, Imported Oil, Environmental Index\}

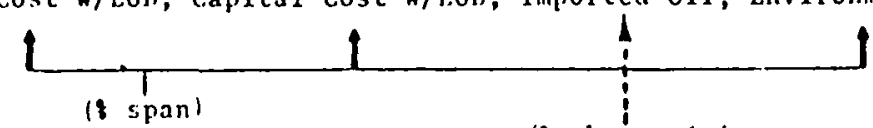
(1) span
(8 above minimum) 
breaks down as follows: the residential and commercial sector uses only 27\% of that of the United States, transportation only 19\%, and industry 58\%. The differential in energy consumption for each of these sectors is made up by elements such as Japan's larger use of passenger rail transportation, smaller consumption for space heat, more efficient iron and.steel industry, etc. These features and their relative contributions are shown in Figure 4.

The industrial sector merits most of our attention because Japan's industrial capacity is second only to that of the United States among industrialized nations and it is here where an intercountry comparison can reveal possibilities of technology transfer. It takes Japanese industry $84 \%$ of the energy use in the United States to make a ton of steel, $62 \%$ for a ton of cement, $82 \%$ for a ton of aluminum, and 93\% for a ton of paper. Most of the difference is obtained because of the more recent vintage of Japan's capital stock, complemented by an almost complete dependence on imports for both fuels and raw materials which by itself promotes thrift. Energy consumption levels outside industry are markedly different between the two countries. We are here searching for technological features that help explain these differences in consumption levels, but what emerges are differences linked to cultural and institutional roots on the one hand, and differences in what traditionally is called "standard of living" on the other. Automobile ownership in Japan is nine persons per automobile versus less than two in the United States, average housing size is $65 \%$ that of the United states according to official statistics (but probably even smaller) and central heating is virtually unknown. Cultural dissimilarities are reflected in the size of the service sector. In Japan institutions such as nursing homes and college campuses are pratically unknown. The third factor influencing energy consumption is geographical and demographic. Population density (733 persons per square mile compared to 57 in the United States) with a distribution predominantly along the coastal areas of the Japanese archipelago has a large impact on demand for 

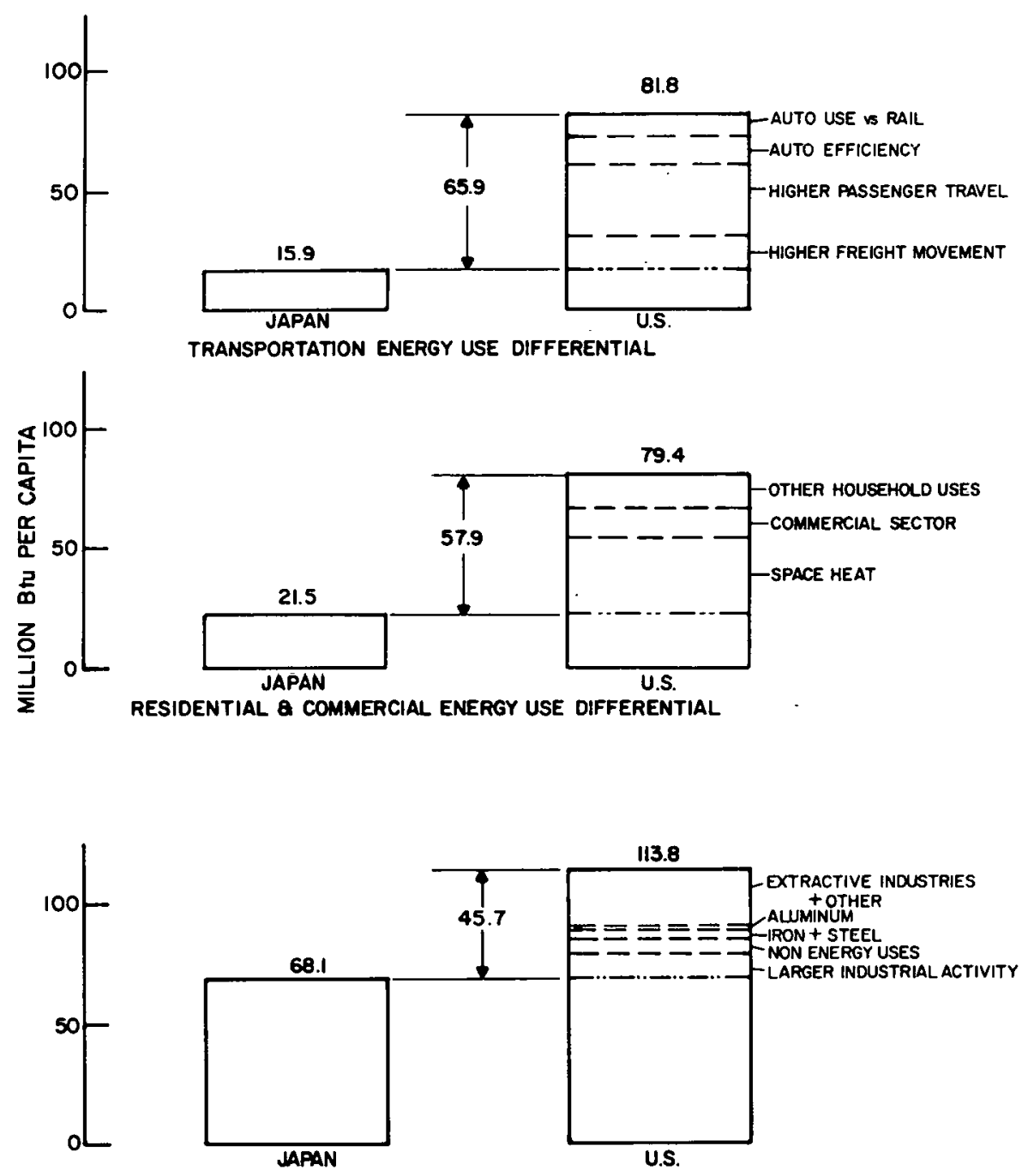

INDUSTRIAL ENERGY USE DIFFERENTIAL

Figure 4. Sectoral Energy Differentials, JapanUnited States 
transportation services. Per capita passenger miles traveled are 33\% of the United States level and freight ton miles 26\% (the latter excludes, however, the important international freight). This lower demand is clearly linked to smaller per capita income, but it is not possible to separate the effects of income from those of demographics. The choice of modes is drastically different, with Japanese passenger miles traveled by rail 50\% higher than the ones traveled by automobile. In the United States, passenger travel by rail is insignificant.

Technological factors that contribute to the per capita consumption differential are present but there are not many examples outside industry.. It is not surprising to find that the automobile fleet in Japan performs $40 \%$ better than the United states average $(19.8 \mathrm{mpg}$ versus $13.8 \mathrm{mpg})$. The superb railroads and extensive subway systems existing in most major cities are very modern and enjoy high occupancies, yielding significantly lower Btu per passenger mile ratios. Energy conversion systems at the household level are less energy intensive in Japan but they would not be considered acceptable to United States homeowners. Stoves and room heaters provide most the space heat $113 \%$ of United States level), table-top burners are used for cooking with less than one third of the households having ovens (consuming $60 \%$ of the United States levels). Solar water heating units are growing at a fast rate and presently are installed in 3\% of all households. Estimates of yearly use per household of other appliances are invariably smaller with lighting at 30\%, refrigeration at $40 \%$, and color television at $50 \%$ of the kWh use of United States homes. Clearly, the major reason in these cases, however, is size of appliances and level of yearly use rather than differences in technological efficiency.

Multinational comparisons of energy use are valuable means. for presentation of information concerning technological features in other countries. They provide insights on the effects of standard of living, population distribution, climate and cultural dissimilarities 
upon energy consumption levels. As a conclustion, in this report we point out:

1) Energy consumption per ton of output is smaller in Japan for energy intensive industries, due in large part to the modernity of Japan's capital stock. Studies of "best practice" processes in the two countries should be pursued in detail.

2) Comparison of efficiency of use in personal consumption of energy emerges as a complex subject inextricably linked to income levels and cultural factors. Among the group of industrialized countries, the case of Japan offers the largest disparity compared to the United States; these variants are minimized when comparing, for example, Northern European nations and the United States.

\subsubsection{Reference Materials System}

The report "Reference Materials System: A Sourcebook for Materials Assessment" was completed and published during the past fiscal year. This report presents a reference set of data pertaining to the materials system, consisting of both renewable and nonrenewable materials, in a consistent manner. The framework used to assemble this information is called a Reference Materials System (RMS). The RMS, a comprehensive systems framework for materials policy analysis, is also useful for carrying out material technology assessment and substitution analysis. The report discusses a few case studies of substitution opportunities of nonrenewables by less energy intensive renewables in the area of containers and packaging, and use of renewables as sources of energy.

Recently, the RMS methodology has been applied to perform net energy analysis. Residential solar heating and cooling, and residential building insulation were the two areas specifically considered. The total materials energy in case of solar heating and cooling was estimated to be about $24 \times 10^{6} \mathrm{Btu} / \mathrm{yr}$. This estimate included the energy required to manufacture a flat plate collector (size $=325 \mathrm{ft}^{2}$-- suitable for use in a single family house) and components used for storage and storage-to-use purposes. A house located in the north-east region and equipped with the above solar 
installation can be expected to harness about $60 \times 10^{6} \mathrm{Btu} / \mathrm{yr}$. of solar energy and thus result in savings of equivalent energy from conventional sources.

In the case of building insulation the net energy effect of using additional insulation in a conventional single-family house to meet or exceed ASHRAE 90-75 standard has been evaluated. specifically, a single-story ranch style house with $1500 \mathrm{ft}^{2}$ floor area and approximately $200 \mathrm{ft}^{2}$ window area, located in the northeast region, has been considered. The building design selected is representative of current construction practices. Fiber-glass insulation of 3-1/2" thickness used both in wall and ceiling of the conventional house is increased to 6" thickness in the modified house. The ratio of energy embodied in the extra insulation to the energy savings per year for the space conditioning of the house under consideration is estimated to be 4.78:7.

\subsubsection{Special Studies and Assistance}

An analysis of the impact of the National Energy Plan (NEP) upon the energy system has been conducted utilizing available energy-economic models to develop Reference Energy systems for two cases. - In the first case demand projections were developed for 1985, 1990, and 2000 assuming the NEP was implemented in its entirety (exclusive of the gasoline tax). In the second case (Base Case) demand projections were developed assuming the NEP was not implemented. Level of services in the projection years, in terms of final demand represented on the right-hand side of the Reference Energy system, are computed using a series of economic models. Long run trends of consumption and investment are obtained from the DRI macroeconomic growth model and input into the DRI inter-interindustry energy model. General economic output obtained from the inter-industry model is then applied to energy-product coefficients from the BNL input-output model, resulting in the Btu final demands shown on the right-hand side of the RES. A more detailed discussion of this methodology is contained in Section 2.3 . For 1985, the mix of fuels satisfying these final demands are 
set equal to the fuel mix specified in the National Energy Plan outlined by the Executive Office of the President, Energy Policy and Planning. Fuels to the residential, commercial, industrial, transportation, and electric utility sectors in 1990 and 2000 are projected according to fuel prices, tax incentatives, penalties, and regulatory policies as outlined in the National Energy Plan. New technology implementation levels were determined by ERDA.

Efficiency improvements are determined from specific proposals in the National Energy Plan. Proposals in the building sector, for example, include a homeowner tax-credit of 25 percent of the first $\$ 800$ and 15 percent of the next $\$ 1400$ spent on approved conservation measures. These proposals are translated into end-use device efficiency improvements such as a reduction in average heat loss per housing unit from an estimate of the number of new and retrofit housing units having a given level of conservation due to fuel prices, tax incentives and other policy proposals indicated above. End-use device efficiency improvements in the Base case were set equal to those in the "moderate price and moderate conservation" projections (SF-2) discussed in section 2.2.2.2.

Total resource consumption in the NEP increases at an annual rate of 2\% from 93 quadrillion Btu's in 1985 to 126 quadrillion Btu's in 2000. Coal consumption increases as a percent of total resources from $21 \%$ in 1976 to $34 \%$ in 2000. An analysis of the market penetration of electric appliances and fuel substitution in residential and commercial buildings indicates the increased use of heat pumps and air conditioning over the next 25 years. Close to one-half of new building construction will utilize heat pumps for space conditioning and $90 \%$ of the building inventory is projected to have air conditioning in the year 2000. In the transportation sector the fleet average fuel economy of automobiles is projected to be $26.0 \mathrm{mpg}$ in $2000,1.5 \mathrm{mpg}$ less than that mandated by the Energy Policy and Conservation Act due to non-optimum engine performance in older model vehicles. Air passenger-miles are projected to grow at an annual rate of $5.4 \%$ from 1985 to 2000 . 


\subsubsection{Decentralized Energy Systems}

The purpose of the project is to analyze in some detail the characteristics of energy systems based on so-called "decentralized technologies." This is a very broad area, which is frequently (if not usually) addressed in the literature without a specific concern with energy supply and demand. The term "decentralized" can refer not only to energy technology, but also to the manufacture of goods, to agricultural production, to political organization and to cultural characteristics. Because of this, the project cannot be limited to a technical study of particular energy supply technologies (although this is one of its major purposes). It must also remain aware of how the technologies fit with the overall objective of decentralization, and of how decentralization can affect the demand for energy and for particular supply and conversion technologies.

of all of the proponents of the "decentralization" movement, none has recently received as much attention, nor spoken as directly to the subject of energy supplies, as Amory Lovins, author of (among other publications) the widely discussed article "Energy Strategy: The Road Not Taken?", which appeared in the October 1976 issue of the magazine Foreign Affairs. Because of this, part of the present project is aimed specifically at an analysis of Lovins' proposals.

Most of the first year's efforts have been involved in data acquisition. The policy strategies and the technologies to support them which are under investigation are both numerous and diverse; much of it has not been studied in depth at BNL or elsewhere. Most of this work is completed; while new information in the many rapidly-developing areas under study continues to be gathered, the main focus of efforts over the past few months has been in the analysis of this information, the creation of "decentralization" scenarios, and the examination of the requirements and implications of these scenarios.

The factors of importance can be divided into three major areas. The first is that of new sources of energy supplies and/or the 
technologies to harness them. Characteristics of these supplies and technologies (although not all have all of these attributes) include a reliance on renewable resources, relatively small environmental impacts, an avoidance of extremely complex "high technology", and a scale of production commensurate with the demands served.

The other two areas arise from what could be called conservation efforts. The first is what is commonly known as the "technical fix"; this area includes technologies which improve the efficiency of energy use, regardless of the source or final demand. Included in this group are such items as better insulation in buildings, improved efficiencies in industrial processes, consumer appliances, etc., and "total energy systems" (taken in a broad sense to include industrial congeneration and district heating from utility power plants).

The final area includes much of what is referred to as "lifestyle" changes. This involves such things as shifts to less energy intensive forms of transportation, substitution of other products for energy-intensive materials, reduction of overlighting and lighted outdoor advertising in commercial buildings, and the like. This area also include changes in demographics and the work/leisure destination which could affect, for instance, the need for commuter transportation.

The energy supply and/or conversion technologies of primary interest in the project are summarized below:

Wind Energy:

This is primarily of interest for its potential use in the generation of electricity. Direct uses of the mechanical energy output of wind turbines, while considered secondary in importance, have not been excluded from study; such uses include direct drive of heat pumps, the pumping of water for irrigation and/or pumped storage hydroelectric facilities, and compression of air for use as a power source for mechanical devices. 


\section{Solar Energy:}

Flat plate collectors have been considered for such uses as water and space heating in residential, commercial and some industrial applications. Concentrating collectors are under consideration for higher-temperature industrial applications and for use in absorption cooling systems. Other cooling techniques which have been examined include night-sky radiation and rock-bed regenerative cooling units (these are restricted to climates with low humidities). "Passive" solar space heating systems have been given considerable attention. Photovoltaics have also been included, with and without concentrators and waste heat recovery. Central station photovoltaic installations or "power towers" have been excluded from the study because of their centralized nature, as have photovoltaic satellite systems.

Biomass Energy:

Most of the attention in this area has been given to the recovery of energy and/or materials from "wastes" of various kinds. These include agricultural wastes (both in the field and in canneries, breweries and the like), forestry wastes, and municipal liquid and solid wastes. Utilization techniques considered for energy recovery from the wastes include direct combustion, anaerobic digestion for methane production, and pyrolysis into liquid or gaseous fuels. Many other techniques are in various stages of development, but these listed are presently the most widely used and are considered to present a good representation of energyrecovery processes. Materials recovery from wastes include paper and metals recycling, and the production of animal feeds and fertilizers. The effects of material recovery on the energy system are indirect, and usually appear as reductions in energy demands in the affected areas.

Total Energy Systems:

Most presently available means of producing electrical power simultaneously produce large amounts of "waste" heat. If this heat can be used to serve thermal energy demands, it is no longer "wasted", 
and overall system efficiency can be greatly improved. Such systems are grouped under the heading of "total energy systems" in this study. They include the traditional concept of total energy systems, which is an internal combustion engine driving an alternator, and from which useful heat is extracted from exhaust gases and/or cooling jacket water. Also included in this group are fuel cell systems with heat recovery, industrial cogeneration systems, utility power plants combined with district heating systems, and photovoltaic array systems with heat recovery.

Hyaro systems:

Primary attention has been given to the potential for small scale hydroelectric systems, particularly the possibility of retrofitting such systems on the many existing dams in the U. S. which do not, at present, produce power.

A wide variety of data relating to the decentralized technologies is of interest in the study. Information gathered has included many areas, including:

- Present status of the technology.

- Energy forms entering and leaving the system (and related efficiencies).

- (Theoretical) Potential implementation levels.

- Appropriateness of the technology to the decentralization theme.

- Economic factors - capital, operations and maintenance, effects of ownership by different economic actors (individuals, corporations, municipalities).

- Environmental effects of manufacture, installation, and normal operation of technologies; also potential accidents and their effects.

- Social and institutional factors, such as employment opportunities, income equity, the need for government regulation, and present legal or social barriers (or inducements) to the use of a technology.

- Reliability and back-up requirements.

- Effects of scale.

Individual technologies are only pieces from which an energy system is built; it is thus required, after the characterization of the technologies, to combine these into a workable, coherent 
whole. This is where most of the efforts of the project are now centered. Two different techniques are being used in this area, which yield very different results.

The first method for developing scenarios is to introduce the rapid growth of decentralized technologies into what is otherwise a "business-as-usual" or base case. This is particularly useful in examining the short-term potentials of these technologies in contributing to the U. S. energy system. Very little in the way of "lifestyle" changes are incorporated into this kind of scenario (except, of course, these implied in the base case). In this analysis, then, the major purpose is to examine how decentralized technologies can augment and complement conventional systems, rather than how (or if) they can replace them.

The second method of scenario development is, in a sense, the reverse of the first. A national energy system based on decentralized technologies is drawn up first, based upon the theoretical potentials of the technologies. An attempt is then made to trace the necessary changes through time for this "decentralized" future to develop from the present system. This method is useful in examining the long-term potential of these technologies. It is in this type of scenario, too, that the effects of "lifestyle" changes are addressed. The possible implications of lifestyle changes are very broad; it is also more difficult, in general, to assess their impacts upon the U. S. energy system than those resulting from technological changes. In addition, the desirability for these changes is under debate even among decentralization proponents. For some, lifestyle changes are the goal of decentralization (rather than, say, environmental quality or reliable energy supplies); for others (Amory Lovins included) they are considered unnecessary or irrelevant.

The quantitative implications of lifestyle changes is one area in which much work remains to be done in the project. The changes under study, and their possible effects upon energy demands, are listed below:

Closer proximity of people's jobs to their homes, reducing commuter transportation requirements. 
Reduction in the use of energy-intensive products, either through substitution (e.g., cotton fibers replacing polyester or simple demand reduction (e.g., less cement production as a result of less new highway construction).

- Changes in agricultural production, including a greater reliance on locally-grown food, a high level of use of agricultural "wastes", a reduction in food processing, and the elimination of most, if not all, petrochemicallyderived fertilizers, herbicides, pesticides, and fungicides.

- Extensive recycling and the elimination of wastes, including a ban on disposable beverage containers, a reduction in packaging materials in general and plastics in particular, and the use of wastes for energy and energy-related products (e.g., fertilizers).

- Greater use of locally available resources and decentralized production, reducing freight transportation requirements (note: decentralized production may increase transportation needs for raw materials as much as it reduces these needs for finished products).

- Greater use of telecommunications to replace business and/or shopping travel.

- Changes in the number of people and/or square footage per household, and changes in household energy demands (e.g. less use of electric appliances, lowered hot water temperature).

- Changes in the requirements for, and use of, commercial buildings: schools, offices, retail stores, government buildings.

- Changes in transportations modes, such as the use of smaller cars, mass transit systems, bicycles, mopeds, etc.

- In addition to the above, people's use of their "leisure time" can have large effects on the demand for transportation, etc. 


\subsection{ECONOMIC ANALYSIS}

\subsubsection{Model Development}

2.3.1.1 Extension of BNL Static Input-Output Model

Drawing on the work of Thomas Sparrow of the University of Houston and of Robert Ayres of the International Research and Technology Corporation, alternative 110-order vectors of time dated input-output coefficients were estimated for the iron and steel sector and for the automobile sector.

Development and estimation of a "dual" version of the static Io model was initiated. This model will permit estimation of future relative prices of the outputs of 110 different sectors, given estimated future year values of capital, labor, and current input-output coefficients, and future year values of the capital/ labor price ratio.

Several improvements were also made in coupling the inputoutput model to BESOM. A "reduced form" version of the combined BESOM-IO model was developed. When debugged, this version will permit simultaneous solution of the combined model, in contrast to the iterative solution procedure currently being used. Several interface equations connecting the BESOM and IO models were also added to the combined model so as to permit estimation of the economic impacts associated with the new energy technologies which were added to BESOM.

2.3.1.2 Coupling of BNL and DRI Models

The current version of the coupling of the DRI economic models with the BNL BESOM, TESOM, or DESOM model is shown in Figure 5 . During FY 1977 the linkage equation inter-connecting the models was formalized and programmed. BNL determines the functional demands in the energy system (the Btu's of space heat, air conditioning, etc.) on the basis of the DRI-determined interindustry groups outputs and final demands, and the DRI-determined interindustry and final demand energy consumption, while DRI determines the price of energy, the composition of energy by type of pricing energy 


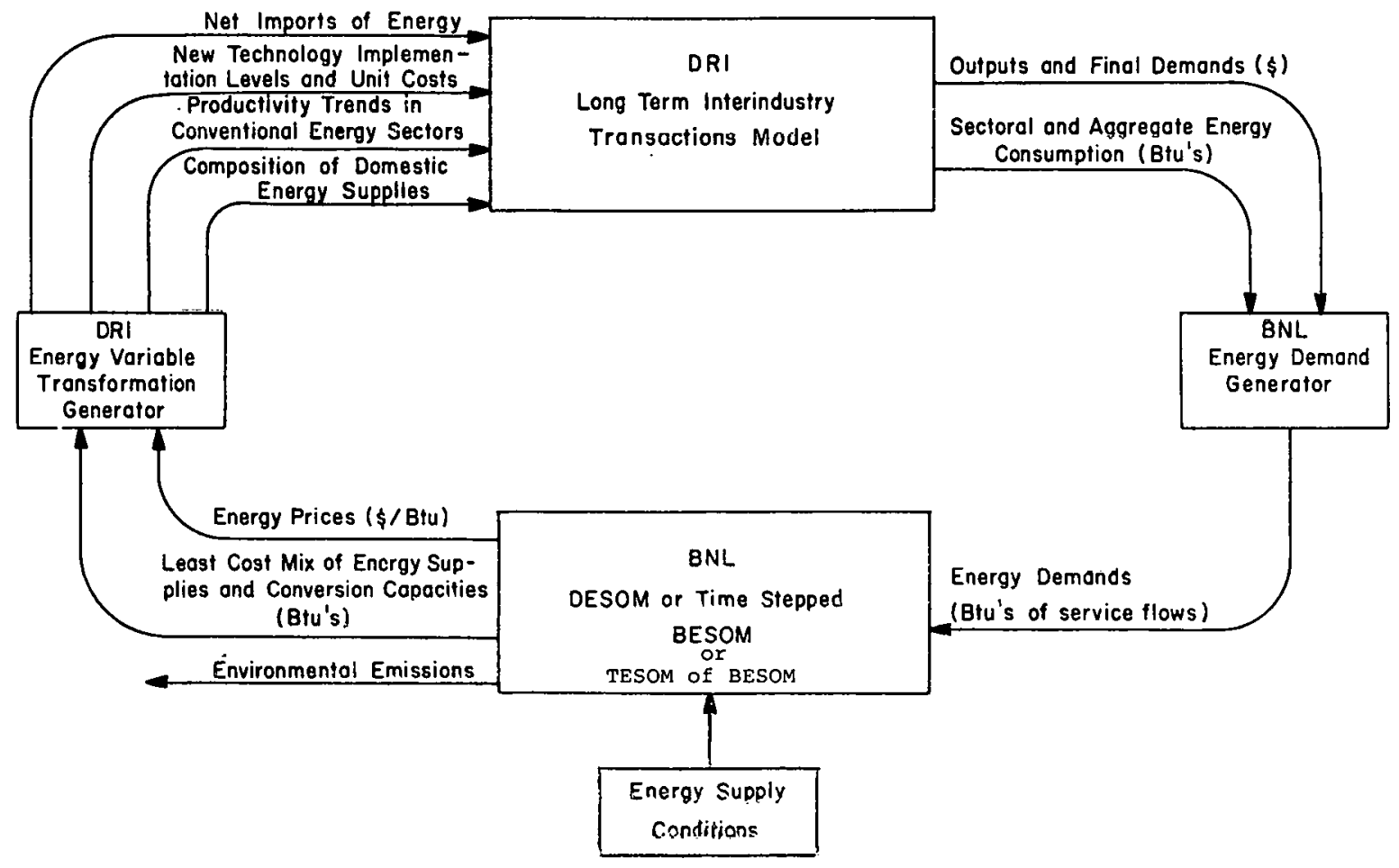

Figure 5. Integrated BNL/DRI Model for Long Term Energy/ Economic/Environmental Analysis 
supply and conversion activity, including new technologies and the amount of imported energy on the basis of BNL determined BESOM, TESOM or DESOM solutions. In addition, work was initiated in using the BNL IO model to further disaggregate the sectoral outputs and prices obtained from the Integrated BNL/DRI Model. During FY 1977, DRI fully integrated the interindustry and growth submodel components of the Long Term Interindustry Transactions Model (LITM). In addition, they added several new energy sectors to LITM.

\subsubsection{Data Estimation}

Eventually, the dual version of the IO model will be used to disaggregate BESOM cost coefficients into capital, labor, materials, and energy components. While this work remains in the development stage, preliminary estimates of the annualized capital and labor components of the cost of new energy technologies were estimated. Reconciliation of all BNL/DRI/ERDA data estimates concerning energy technology costs was begun.

In addition, trends in gross labor production from 1967 to 2000 were estimated for each of the 110 sectors in the BNL IO model. These estimates will be used in the dual version of the Io model to estimate changes in relative prices over the 1967-2000 period.

\subsubsection{Model Applications}

\subsubsection{Development of ERDA Energy Projections}

Using the BNL IO and BESOM models, and the DRI LTIM model, four alternative energy/GNP projections were estimated for ERDA for the 1985-2000 period, where each projection corresponded to a different level of new energy supply, conversion and end-use technology and a different set of supply prices for crude oil, crude gas, coal and uranium.

\subsubsection{Economic Analysis, Third ERDA RD\&D Plan}

The SF-2 set of energy/economic projections was used as a reference against which the effects of four alternative future sets of economic and energy policies were estimated. In one set (Case Set 1A), the base case 1985-2000 GNP growth rate was decreased from 
3.5\% per year to $2.3 \%$ per year and the linked BNL/DRI model structure was used to estimate changes in labor force, productivity, energy consumption, and energy price time trends consistent with the assumed change in the GNP growth rate. In another set (Case Set 1B), potential future non-price energy conservation measures (over and above those assumed in SF-2) were added to the case Set IA scenario specifications. In a third set (Case set 1C) the base case 1985-2000 GNP growth rate was increased to 4.2\% per year, and the assumed base case SF-2 supply prices of coal, crude oil, crude gas, and electricity were decreased to a set of prices corresponding to an $\$ 8 / \mathrm{bbl}$ price of oil in 2000 , in 1975 dollars.

In another set of parameterizations upon the SF-2 base case energy-economic projections, maximum oil and gas import target constraints were added to SF-2 scenario specifications and the linked DRI/BNL model was used to estimate GNP and energy responses associated with these input constraints.

\subsubsection{Special Studies}

In addition to the above applications performed for and in consultation with the Assistant Administrator for Planning, Analysis and Evaluation of ERDA, BNL and DRI jointly participated in the Stanford Energy Modeling Forum and a modeling panel of the Summer Operations Research Society of America chaired by Charles Hitch, President of Resources for the Future. The latter study entitled "The Long-Term Economic and Environmental Consequences of Phasing Out Nuclear Electricity", was published by Resources for the Future.

In the base case scenario of this study it is assumed that growth in the nuclear sector will not be constrained by safety or security considerations, so that, when economical, nuclear reactors will build up at reasonable rates, including advanced uranium and breeder reactors, starting in 2000 .

In each of three alternative scenarios, future nuclear capacity is limited to that capacity which is either currently in operation or under construction, while coal production is permitted to expand, at most, by $5.4 \%$ per year, $7.2 \%$ per year, 
and $3.0 \%$ per year, in cases $\mathrm{Cl}, \mathrm{C} 2$, and $\mathrm{C} 3$, respectively. In $\mathrm{C} 3$, shale oil production is also limited to a maximum of 15 quads in 2020. The same set of current "best practice" environmental abatement costs and of emission coefficients are used in generating each of the four alternative futures. Thus, all the following conclusions are contingent upon the assumption that future environmental regulations will remain at current "best practice" levels.

In case the construction of all prospective additional nuclear plants is stopped as a result of government policy, economic impacts will be minimized if most of the prospective nuclear plants are replaced by coal-fired plants. However, in order to minimize economic impacts, coal production would have to expand at the maximum $7.2 \%$ per year rate specified for scenario $\mathrm{C} 2$. In $\mathrm{C2}$ relative to the Base, oil import consumption would decline slightly in all periods. In the near term to 1990, real consumption of all goods and services by households would actually increase slightly above Base Case amounts in $\mathrm{C} 2$, since construction costs for coalfired plants are assumed to be less than those for nuclear plants. over the longer term to 2020, both real GNP. and real household consumption would decline slightly from Base Case amounts in C2, since the prospective long run average cost of producing coalfired electricity is expected to be greater than that for nucleargenerated electricity. By 2020, real household consumption is 1.68 less in $\mathrm{C} 2$ than in the Base.

Practically all energy-sector related air, water, health and land use effects would increase significantly above Base Case rates in $\mathrm{C} 2$, particularly in the post-1995 period. For example, by 2020 , in $\mathrm{C} 2$, relative to the Base, $\mathrm{SO}_{2}$ emissions increase by $100 \%$, suspended solids by $250 \%$, man-days lost by $125 \%$, and land use by $25 \%$. Only radiation levels are reduced in $\mathrm{C} 2$.

Since those nuclear plants which are either currently in operation or under construction would remain in operation in the near future in $\mathrm{C} 2$, more adjustment from prospective Base Case energy patterns would be required in the post-1995 period than in 
the period to 1995. In order to ensure sufficient additional coal production in this latter post-1995 period, however, coal production capacity might have to be expanded in the earlier pre-1995 period at rates exceeding current needs, so as to circumvent any potential bottlenecks in the post-1995 period. Unless coal producers were willing to tolerate fairly substantial losses during this early period, some government subsidies to coal producers might be required to ensure the cost-minimizing near term expansion rates of coal production.

If coal production did not expand at the maximum rate of $7.2 \%$ per year indicated for $\mathrm{C} 2$ over the near term because of physical constraints on expansion capabilities, and/or lack of near term profitability, and/or of a conscious policy desire to limit coalrelated environmental impacts, only small additional economic impacts would result as long as the reduction in the coal expansion rate was moderate. In case $\mathrm{Cl}$, the maximum coal expansion rate was reduced to $5.4 \%$ per year, as opposed to the $7.2 \%$ per year rate for C2, Relative to C2, household consumption declines by small amounts in $\mathrm{Cl}$ in all years. The declines are greater in the post1995 period, when some high cost solar electricity plants are introduced in $\mathrm{Cl}$ to replace coal based plants in $\mathrm{C2}$. However, real consumption in $\mathrm{C} 2$ never declines by more than $4 \%$ relative to that in $\mathrm{Cl}$.

In addition, environmental emissions also do not decrease substantially in $\mathrm{Cl}$ relative to those in $\mathrm{C} 2$, as most of the cutback in aggregate coal consumption in $\mathrm{Cl}$ relative to that in $\mathrm{C} 2$ would take the form of less use of coal for production of synthetic fuels, a relatively non-polluting activity. Moderately higher cost amounts of oil imports and of domestic shale production would be used in $\mathrm{Cl}$ to replace the coal-based synthetic fuels.

on the other hand, if future coal and shale oil production is consciously constrained by public policy, along with the assumed constraints imposed upon nuclear power, the economic impacts would be severe indeed. In the $\mathrm{C} 3$ case, in which coal is constrained to 
a maximum of 50 quads in 2020, and shale oil to 15 quads, (versus the 78 quads and 7 quads used, respectively, in the base in 2020), aggregate consumption of all goods and services would decline by escalating amounts over time relative to the Base. By 2020, aggregate consumption of all goods and service declines $21.6 \%$ in C3 relative to the Base. Between 2000 and 2020 per capita real consumption of all goods and service still increases in C2, but at only one half the $2.0 \%$ per year Base Case average annual rate.

The primary reason for these large economic impacts is the extremely high capital cost assumed for solar central station electricity plants. Persuant to instructions given to all model participants in this exercise, the capital cost for solar electric capacity was specified at 3.3 times the capital costs for coal electric capacity. The long run policy implication of these results for the $\mathrm{C} 3$ case is obvious - any decision to limit future dependence on coal, shale and nuclear supplies will exact large economic penalties, unless solar costs can be reduced substantially and/or unless substantially greater than assumed amounts of oil and natural gas supplies can be developed domestically or imported.

As a result of sharp declines in aggregate energy consumption and increases in the relative importance of solar contributions in $\mathrm{C} 3$ (relative to $\mathrm{Cl}$ and $\mathrm{C} 2$ ) much fewer environmental residuals are generated in $\mathrm{C} 3$ than in $\mathrm{Cl}$ or $\mathrm{C} 2$. However, the production of most types of residuals, except those related to nuclear radiation, is generally higher in $\mathrm{C} 3$ than in the Base. Thus, a policy decision to cut back on prospective future amounts of coal and shale oil production while simultaneously halting further nuclear construction activity will lead to few environmental benefits, while exacting a large economic penalty. 


\subsection{ENERGY MODEL DATA BASE}

\subsubsection{Data Base Development}

The new technologies data file, compiled from information provided by Hittman Associates and Teknekron, Inc., has been added to the Energy Model Data Base (EMDB). A package of standard data base printouts and an updated user booklet have been prepared.

Information on toxic and hazardous non-radioactive trace element pollutants (19) were gathered for BNL under a subcontract. These data, which include coefficients for arsenic, chromium cyanides, hydrogen sulfide, lead, magnesium, mercaptans and zinc, among others, with reference to fossil energy technologies, the nuclear fuel cycle, and geothermal and solar energy technologies, will be incorporated into the EMDB.

\subsubsection{Model Development}

An activity-level version of the Energy System Network Simulator model has been developed. An interactive computer program was implemented which permits rapid computation of energy flows and resultant emissions associated with the network shown in Figure 6. The program has been used to calculate impacts for perturbations on the Sourcebook (2) RES's.

The ESNS model was updated to include all the new technology processes to be added to the EMDB. A computer code allowing interactive access to the ESNS model has been compled.

In conjunction with the Biomedical and Environmental Assessment Division, an ESNS/BESOM interface was programmed and validated that tabulates disaggregated emissions levels based on the results of the optimization model.

\subsubsection{Analytical Support}

The Regional Emission Projection System (REPS) was installed on BNL's computer by its developers, BoozAllen \& Hamilton, Inc. NEDS/REPS is a computerized air pollution emissions model which projects annual emissions for the five criteria pollutants in any 


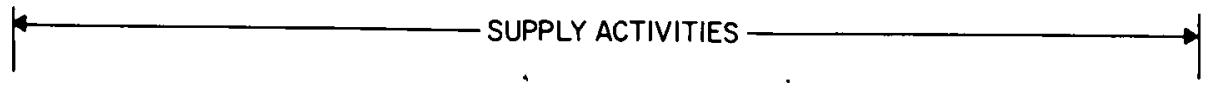

NUCLEAR: (LWR,LMFBR, HTGR, CTR)

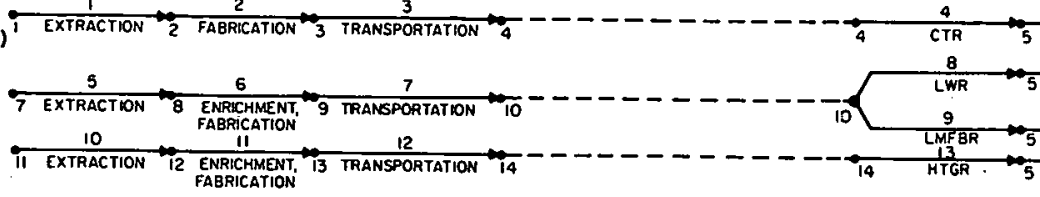

HYDROPOWER

GEOTHERMAL

$\stackrel{17}{i 8 \quad \text { WELL }} \rightarrow$

SOLAR:

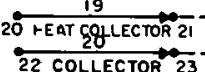

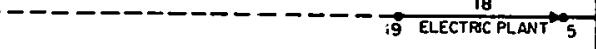

SHALE OIL:

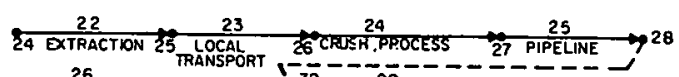
29 CFWEDMPORTS

REFINEDIMPORTS $30^{\circ}$ DOMESTIC WELLS 31 TRANSPORT 28 REFINERY 33 O15TRI

COAL: 35. S17P MMNE

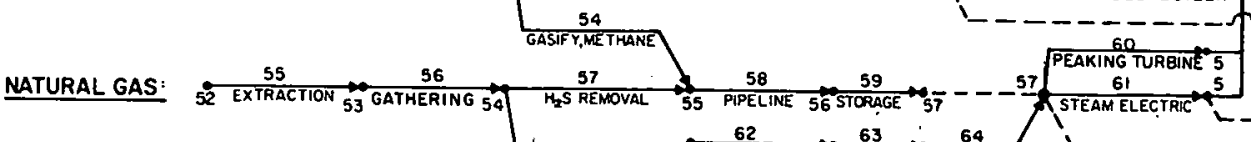

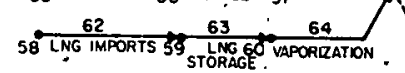

INTERMEDIATE ENERGY FORMS
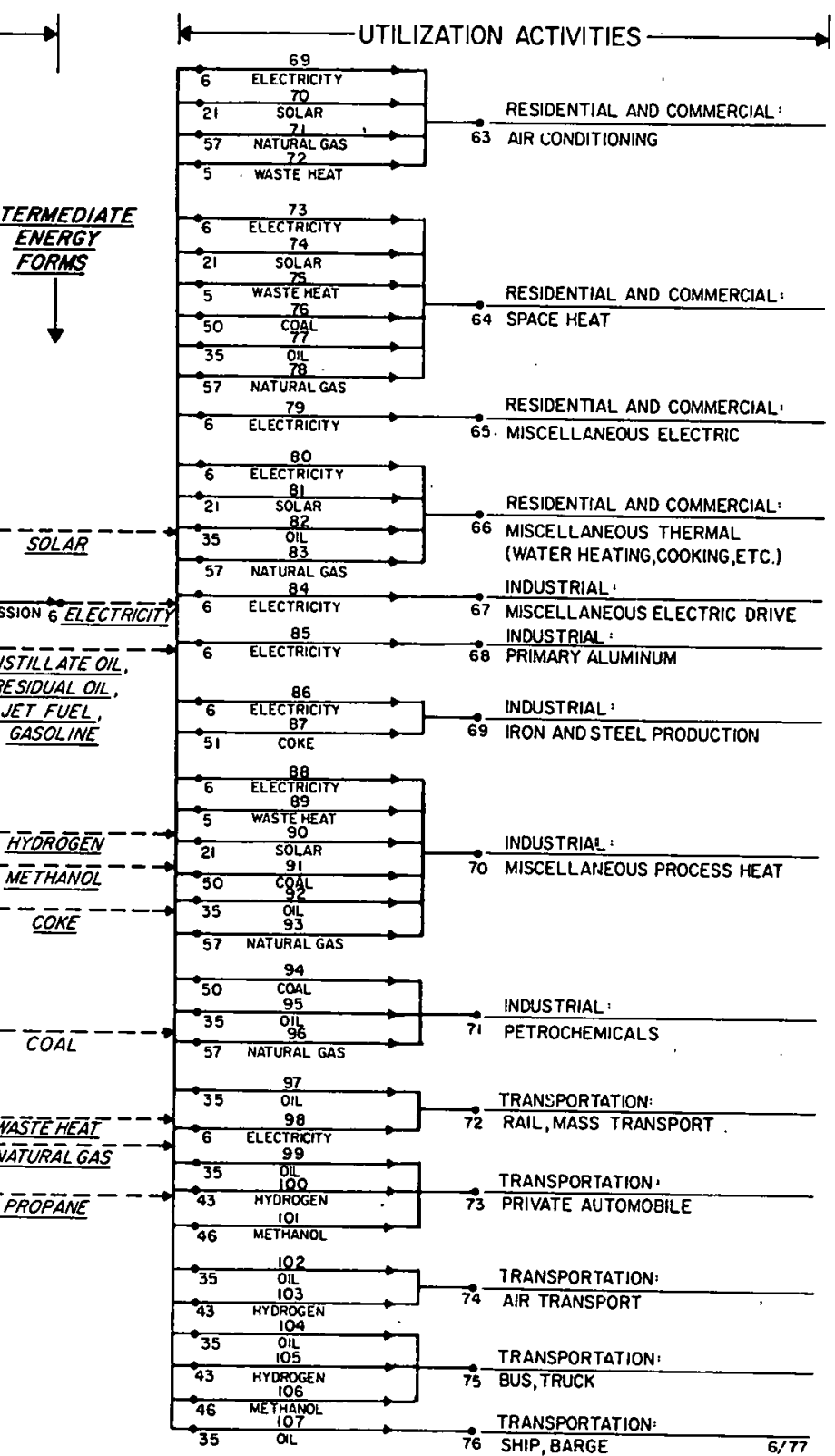

Figure 6. National Energy System Network for ESS Model 
of the 243 Air Quality Control Regions (AQCR's), or for the U: $S$. as a whole. The Environmental Protection Agency's National

Emissions Inventory (NEDS) establishes the baseline/emission levels while OBERS or economic forecasts are employed to compute growth factors. Projections may be made for any year between 1974 and 2000, and are adjusted to include the effects of present and future control regulations. Among other output data, the model gives point source emission levels by 6-digit SCC code, transportation emission factors, and area source activity levels.

In order to use REPS efficiently on the BNL computer, several programming changes were effected which resulted in substantially reduced computation time.

An analysis of the environmental impacts of future energy development in Montana for the years 1985 and 2000 was undertaken for APAE/OEA in collaboration with Hittman Associates. Using the REPS model, generation of particulates and $\mathrm{SO}_{\mathrm{x}}$ by existing and proposed point and area sources was determined. Area source residuals were summed by county; a five kilometer grid was overlaid on Montana and each grid unit was identified by county; residuals were distributed over the grid. The resulting information was input to the Climatological Dispersion Model (20) which relates emission levels to air quality.

Effort was initiated on an analysis of the President's National Energy Plan (NEP), with the objective of examining environmental impacts at the AQCR level. The results of the REPS model were calibrated to the Federal Energy Agency's PIES model runs. To accomplish this task, many modifications were made to REPS including updating of the emission factor file, correction of the fuel calculation algorithm, and data screening.

As a supplement to the REPS five criteria air pollutant inventories, a separate program (TEX) summarizes emissions of additional pollutants. These include air and water toxics as well as standard water pollutants. 


\subsubsection{User Assistance}

Under International Energy Agency (IEA) funding, a version of the ESNS model was developed which incorporates definitions of demand sectors, fuel types, and supply processes tailored to IEA needs. An interactive interface program, PERTURB, facilitates access to EMDB entries.

Assistance was provided to the Committee on Nuclear and Alternative Energy Strategies in the form of data review and design of new technology trajectories.

As directed, data and model tapes and information were supplied to outside users of the data and models. Work was begun on preparing an updated technical report of user's guide for the REBS system in conjunction with Booz-Allen \& Hamilton. 
3.0 PROGRAM PLAN FOR FY 1978

3.1 ENERGY MODELS

3.1.1 System Optimization Models

BESOM will be maintained and updated to reflect latest information on research and development progress and analytical needs of DOE. Increased regional detail will be emphasized, particularly regional environmental impacts and constraints. Under a separate contract. with the Electric Power Research Institute, the time-phased model, DESOM, was reformulated and programmed in PDS/MaGen. Sensitivity studies will be performed with this model, including an analysis of the effect of the discount factor assumption.

\subsubsection{Support}

Technical assistance will be provided to the Department of Energy on special topics to be identified. Assistance will also be provided indirectly through aid given to other groups performing DOE tasks. Modeling refinements and report writing capability will be added as required. Every effort will be made to ensure quick response to DOE needs.

\subsubsection{Regional Energy Model}

Work will be completed on the first version of the nine region version of BESOM. The electrical sector will be reformulated, in order to allow interregional transmission without substantially increasing the size of the problem.

Incorporation of input/output parameters will be explored.

The model will be in operating order and will be used for a demonstration analysis. A topical report will be prepared jointly with other NCAES programs participating in this task.

\subsubsection{Time-Stepped Version of BESOM}

Work will be completed on the time-stepped version of BESOM. Algorithms for calculating possible penetration rates of new technologies, or changes in preferences for established technologies, will be developed or adopted. Dynamic features of other energy models will continue to be explored. Demonstration runs will be made and a topical report prepared. 


\subsection{TECHNOLOGY ASSESSMENT}

\subsubsection{Interfuel Substitution Studies}

A study analyzing renewable resources (solar and geothermal energy potentials) will be initiated, including the use of fuels from biomass emphasizing varied sources such as agricultural biomass crops and agricultural and municipal wastes (including sewage). Environmental and economic impacts will be stressed.

\subsubsection{Technology Studies}

Efforts begun in FY 1977 will be continued and expanded, particularly because of the strong orientation toward DOE planning needs. More detailed technology characterization will be incorporated in the energy models used for analysis.

As time permits, work will be directed toward a revised edition of the Sourcebook for Energy Assessment. This will incorporate revised demand estimates evolving from recent forecast work, amended implementation levels for new technologies, updated cost information, and in general will contain more detailed information considered necessary for energy assessment. New Reference Energy Systems will be generated in the course of this effort.

\subsubsection{Introduction Rates of New Technologies}

Work on the development of a methodology for estimating penetration rates of new technologies which has been deferred because of other priorities, will be resumed.

\subsubsection{Trans-National Comparisons}

A report on energy use in Japan vis-a-vis the United States will be issued early in FY 1978, and a study of a Third World nation will be considered.

\subsubsection{Reference Materials Model}

A study of the application of the Reference Materials Model to solar heating applications and conservation will be completed, using the data previously developed under this task. It will assume two potential levels of solar implementation, and will then assess the material, embodied energy, and economic requirements 
for carrying them out. Domestic and foreign resource requirements will be considered, environmental effects evaluated, and social and institutional problems and barriers outlined. Similarly, use of insulating materials as a conservation option will be assessed. 3.2.6 Special Studies and Assistance

All special tasks requested will be given the highest priority response, using the interdisciplinary approach which has proven successful in past programs. Continuing efforts will be geared toward the coordination and state of readiness required to carry out these on going efforts in an expeditious manner.

\subsubsection{Decentralized Energy Systems}

Part II of this study, an analysis of the strategy of Amory Lovins, will be performed. The emphasis will be on the incorporation of these technologies into the RES and BESOM for purposes of evaluation. The following guidelines will be used:

1. Reestablish demands to incorporate his definition of "conservation".

2. Appraise his increased efficiencies--are they truly obtainable?

3. Implement his "soft" technologies in appropriate timeframes with proper utilization factors.

4. Assess financial and environmental impacts.

5. Analyze social and political implications.

6. Ascertain strengths and weaknesses of his concepts.

7. Identify gaps which may result from use of "soft" technologies.

8. Assess potential of filling the gaps--need for backup systems, etc.

A topical report covering this phase of the work will be prepared. 


\subsection{ECONOMIC ANALYSIS}

\subsubsection{Model Development}

3.3.1.1 Extension of Input-Output Model into an Interindustry Linear Programming Model

Work will be initiated on a plan for an economy-wide linear programming model. This model will choose between alternative interindustry processes so as to either minimize total costs for producing a specified level and mix of GNP, or maximize the level of GNP for given availabilities of capital, labor, and resources.

This model, when completed, would permit estimation of both the energy and economic impacts associated with the introduction of new energy conversion and end use technologies, as well as the penetration rates of the new technologies by type of industry.

A plan for the development and estimation of this model, involving other participants, will be completed.

3.3.1.2 Development of an Input-Output Pricing and Employment Model

Work on the development and estimation of a dual version of the 110 sector input-output model will be completed. Historical values of the 110 sector value added variables will be disaggregated into their capital and labor, and price and quantity components. A methodology for estimating future changes in these variables will be developed. Specific attention will be paid to the analysis of expected energy-related capital and labor trends (e.g., increases in the capital intensity of petroleum refining due to a greater emphasis on offshore mining activities). Estimated changes in non-energy related capital and labor requirements will be tied to estimates of HJA, Clopper Almon of the University of Maryland, and Roger Bezdek of DOE.

This model will be used to estimate detailed 110 sector order prices, employment, and capital requirement trends associated with the annual DOE plans. Work will be initiated on the use of this model for disaggregating price trends emerging from the DRI LTIM model. Work will also be initiated on using these disaggregated price trends, in turn, to estimate BESOM cost coefficient trends. 
3.3.1.3 Extension of the Time Frame and the Non-Energy Sectoral Detail of the HJA LTIM Model

The time frame of the DRI LTIM model will be extended to 2025 . In addition, HJA will initiate work on extension and reestimation of the non-energy sectoral detail of the LTIM model, using 1972 Io statistics developed by the Bureau of Economic Analysis if available. An investigation will be made of the feasibility of developing more disaggregated nonenergy sector links between the BNL models and the expanded LTIM model.

3.3.1.4 Coupling and Integrating Current BNL and HJA Models

Development and estimation of the following BNL/HJA model inter-relationships will be completed in FY 1978: 1) HJA will expand the energy sector detail of LTIM so as to incorporate BNL/DOE estimated values of future new energy technology input requirements. To the maximum extent feasible, given the different production and pricing structures employed in BESOM, IO, and LTIM, the annualized total costs of operating unit levels of new energy technologies will be the same for all models. The actual list of new energy technologies to be included in this model linkage will be specified jointly by BNL, HJA and DOE. This methodology will replace the incremental capital and labor linkage relationships used in previous BNL/DRI model runs for ERDA. 2) BNL and HJA will jointly develop and estimate linkage relationships to link BESOM end use demands and efficiencies to HJA determined total primary energy consumption demands. Two versions of this linkage relationship will be developed and estimated: One, for determination of base case reference projections, will incorporate the BNL IO model determined product demands. The other version, used for determination of changes from base case reference projections, will link LTIM-determined aggregate energy assumption changes to changes in BESOM demands, via income and price elasticity estimates.

Development and estimation of the following BNL-HJA model inter-relationships will be continued in FY 1978. 1) Linking HJA determined non-energy prices to BNL BESOM cost coefficients for 
energy supplying and energy conversion activities. Eventually this linkage will employ either the dual version of the 110 sector IO model to disaggregate HJA determined aggregrate prices (e.g., for manufacturing) or will employ price merging from the expanded non-energy sector DRI mode. 2) Integrating energy supply models into the coupled BNL/HJA framework. Two alternative methodologies and estimating procedures will be pursued: In one, energy supply activities in BESOM will be characterized by step functions, each step describing how much of given type of resource is available at a specified cost. The step function relating costs to potential annual amounts supplied will be estimated either by DOE for planning applications or by $\mathrm{HJA}$ on the basis of simulation of selected energy supply models which are both currently available to HJA and not subject to proprietary restrictions. In another framework, DESOM will be used as the energy supply model, replacing BESOM. HJA, BNL or DOE estimated step functions relating total supplies (to at least the year 2020) to costs will be attached to DESOM.

Development and estimation of the following BNL-HJA model interrelationships will be initiated in FY 1978. 1) Development of a methodology to determine potential amounts and effects of non-price and non-income shifts on energy demand; 2) estimation of convergence properties of the entire linked BNL/HJA model, and development of solution algorithms.

3.3.2 Data Estimation

3.3.2.1 Estimation of Alternative Process Input Requirements For selected intensive energy using sectors (e.g., iron and steel) and/or for selected energy-intensive energy using activities occurring across many sectors (e.g., process heat), work will continue on estimating alternative vectors of input requirements, one for each type of process identified. These estimates will be used in the model described in 3.3.1.1.

\subsubsection{Labor and Capital Coefficients}

Trends in labor and capital coefficients will be estimated to the year 2000 for insertion in the dual version of the Io model described in 3.3.1.2. 


\subsubsection{Applications}

3.3.3.1 Development of Energy Projections

Using the HJA and BNL models, alternative conditional projection sets will be estimated for the 1985-2000 period, where each projection will correspond to different levels of energy supply and conservation technology in relation to the level of economic activity. The general specifications of each scenario will be provided by DOE. HJA will provide the macroeconomic projection for these projections.

\subsubsection{Social Welfare Analysis}

Work on relating model outputs to an analysis of social welfare will continue. The methodology employed will continue to draw on both estimated trends in detailed variables such as room temperature, cubic feet of space per room and per house, and so on, and on the more aggregate trends in constant dollar consumption expenditures.

\subsubsection{Other DOE Support}

Upon DOE request, the BNL and HJA models and data will also be used for any other Planning and Analysis support activities. Any effort described under this task will affect the scheduling of work on coupling the HJA and BNL models described under 3.3.1. 


\subsection{ENERGY MODEL DATA BASE}

\subsubsection{Date Base Development}

The Energy Model Data Base (EMDB) will be maintained and updated on a continuing basis. Toxic trace element emission coefficients will be added in the system 2000 format. Programming of computerized interfaces to NCAES models will be undertaken. Development of a regional water quality and availability data base, starting with the Northeast Region, will begin.

\subsubsection{Model Development}

Versions of ESNS will continue to be modified and refined to meet specific analytical needs. The NEDS/REPS package will be maintained and enhanced.

\subsubsection{Analytical Support}

The NEDS/REPS model will be applied to policy analysis questions of joint interest to BNL and DOE. BESOM will be examined with regard to the environmental insights that may be drawn from it. A plan will be developed for including effluent charges, control cost curves, and/or an environmental objective function.

\subsubsection{User Assistance}

The updated technical and user's guide to the NEDS/REPS

system will be completed. Assistance with data questions will be provided to users both within and outside the NCAES. 
REFERENCES

1. Reference Energy Systems and Resource Data for Use in the Assessment of Energy Technologies, Report No. AET-8, Associated Universities, Inc., Upton, N. Y., April 1972.

2. Beller, M., Ed., Sourcebook for Energy Assessment, BNL 50483, December 1975 .

3. Cherniavsky, E., Brookhaven Energy System Optimization Model (BESOM), BNL 19569, Energy Technology Assessment Division, Brookhaven National Laboratory, Upton, L. I., N. Y. December 1974 .

4. Goettle, R. J., Cherniavsky, E. A., and Tessmer, R. G., An Integrated Multi-Regional Energy and Interindustry Model of the United States, BNL 22728, National Center for the Analysis of Energy Systems, Brookhaven National Laboratory, Upton, New York, May 1977.

5. Hermelee, A. L., Regional Reference Energy Systems, EPRI EA-462, Prepared for the Electric Power Research Institute: 3412 Hillview Avenue, Palo Alto, California, June 1977.

6. American Gas Association, Gas Facts: A Statistical Record of the Gas Utility Industry, Department of Statistics, American Gas Association, 1515 Wilson Bldg., Arlington, Virginia 1975 Edition.

7. U. S. Department of the Interior, Bureau of Mines, Various news releases regarding energy production and consumption.

8. Edison Electric Institute, Statistical Yearbook of the Electric Utility Industry, 1975, Edison Electric Institute, 90 Park

Avenue, New York, N. Y., October 1976.

9. Federal Power Commission, Bureau of Power, Annual Summary of Cost and Quality of Steam-Electric Plant Fuels, 1975. Federal Power Commission, Washington, D. C., May 1976.

10. Federal Energy Administration, Office of Energy Information and Analysis, Monthly Energy Review, Federal energy Administration, Washington, D. C. Selected Issues.

11. Shaw, M. L. and Wood, R. K., Volumes and Transportation Costs of Fossil Fuels Shipped between Census Regions, BNL 21995, Prepared by Logistics Management Institute, Washington, D. C., for the Economic Analysis Division, Brookhaven National Laboratory, October 1976. 
12. Federal Energy Administration, 1976 National Energy Outlook, FEA-N-75/713, U. S. Government Printing Office, washington, D. C., 1975 .

13. Gunwaldsen, D., Ghagat, N., and Beller, M., A Study of Potential Coal Utilization: 1985-2000, DRAFT, National Center for the Analysis of Energy Systems, Technology Assessment Division, Brookhaven National Laboratory, Upton, N. Y., July 1977 .

14. Griffin, J. M., Long-run Production Modeling with Pseudo Data: Electric Power Generation, The Bell Journal of Economics, Volume 8, Number 1 , Spring 1977.

15. Behling, D. J. et. al., A Hierarchical Framework for Modeling Energy, Economic, and Environmental Policy Impacts at the Local, Regional, and National Levels, DRAFT, National Center for Analysis of Energy Systems, Brookhaven National Laboratory Upton, N. Y., September 1977 .

16. Zionts, S., and Wallenius, J., An Interactive Programming Method for Solving the Multiple Criteria problem, Mgt. Sci. 22, 652-63, February 1976.

17. Regional Emission Projection System, System Documentation (User's Guide), Booz-Allen \& Hamilton, Inc., Bethesda, Maryland, for ERDA, January 1977.

18. Regional Emission Projection System, System Documentation, Booz-Allen \& Hamilton, Inc., Bethesda, Maryland, Report No. 9075-014, for EPA, April 1975.

19. Toxic Trace Pollutant Coefficients for Energy Supply and Conversion, Hit-705, Hittman Associates, Inc., Columbia, Maryland, for ERDA, APAE, September 30, 1977 .

20. Busse, A. D., and Zimmerman, J. R., Users Guide for the Climatological Dispersion Model, EPA-R4-73-024, (Dec. 1973). 


\section{APPENDIX A}

\section{INDUSTRIAL PROCESS MODELING}

The energy use of several major industries such as steel, paper, cement, aluminum, etc., accounts for a large proportion of the energy demand in the process heat category. BESOM now provides an option to disaggregate the energy consumption of the cement industry from the process heat sector for analytic purposes. With respect to the manufacturing process, the energy use can be described by the simplified diagram (Fig. A-1). Essentially, it involves (1) grinding the correct proportions of clay and lime-containing materials, e.g., limestone, cement rock, clay, iron ore, etc., to powder or slurry, (2) burning the mixture in a kiln until fused, (3) grinding the clinker that comes out of the kilns with gypsum into finer powder. coal, gas and oil are burned in the kilns to produce heat and the grinding mills are driven by electricity. The processed cement may be mixed with waste material, usually by-products from other industries, such as steel, clay, paper, up to $20 \%$ of the total volume. Some kilns burning gas and oil may be converted at some expense to burn coal. 

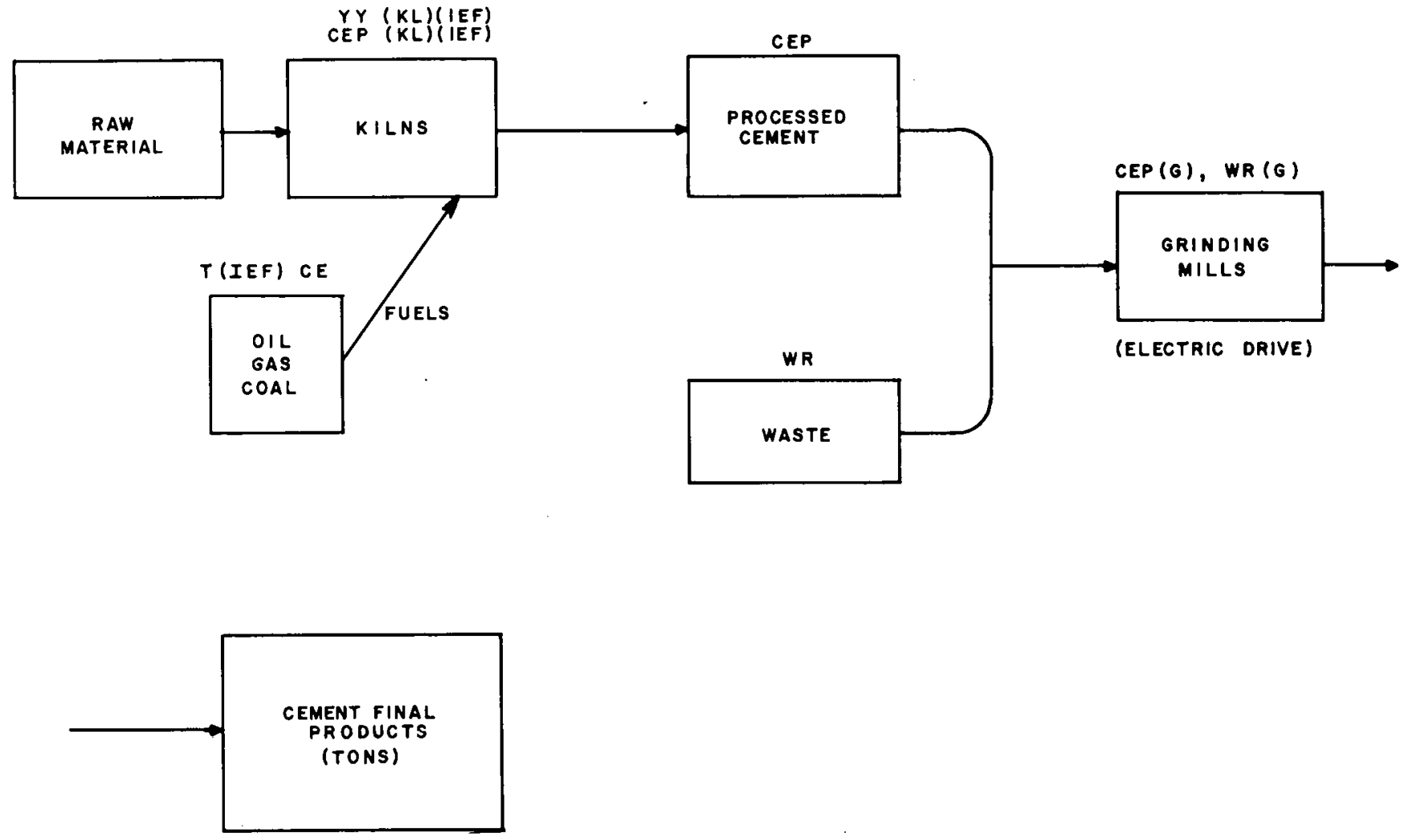

Figure A-1. Cement Manufacturing Process 
Definition of Variables

1. $\quad \mathrm{YY}(\mathrm{KL})(\mathrm{IEF})$ : Capacity of kiln type (KL) using fuel $(\mathrm{IEF})$, where $\mathrm{KL}=01,02, \ldots, 11,12$.

2. $A Y(K L)(I E F)$ : capacity of kiln type (KL) using fuel type (IEF) converted from other fuel types.

3. $T(I E F) C E$ : fuel (IEF) delivered for cement process:

4. DRELECE: electricity consumed by grinding process.

5. $\operatorname{CEP}(\mathrm{KL})(\mathrm{IEF})$ : cement produced in kiln (KL) burning fuel (IEF).

6. CEP (KL): total cement processed in kiln (KL).

7. CEP: total cement produced.

8. $\operatorname{CEP}(G)$ : the amount of cement through grinding process (G), for $G-1,2$.

9. WR: total waste used to mix with cement

10. WR $(G):$ the amount of waste through grinding process (G), for $G=1,2$

* The units of $Y Y(K L)(I E F), A Y(K L)(I E F), C E P(K L)$ (IEF), CEP(KL), $\mathrm{CEP}, \mathrm{CEP}(\mathrm{G}), \mathrm{WR}, \mathrm{WR}(\mathrm{G})$ are $10^{6}$ tons, the rest are in quads.

Bound set:

Variables $Y Y(K L)$ (IEF) are upper bounded by data in TABLE KILNINP ((IEF), (KL)). 
Description of Equations:

There are seven types of equations which are used to describe the formulation of the cement production model.

a. The demand equation insures that the total cement output meets the demand required (in $10^{6}$ tons). It reads DCE: CEP + WR = TABLE REQUIRE (E6TONS, CE).

b. Fuel usage equations describe how the fuels are consumed in the cement production. The coefficient represents energy used per ton of cement processed in kilns. FUL (IEF) CE: T (IEF) CE $=\sum$ CEP (KL) (IEF) *TABLE $\mathrm{KL}$

$$
\operatorname{KILNCAP}(\mathrm{COEF},(\mathrm{KL}))
$$

Also, the electricity used in the grinding processes is described in the following equation:

QELECE: DRELECE $=\sum \operatorname{CEP}(G) *$ TABLE $\operatorname{ELECUSE}(\operatorname{CEP},(G))$

$$
\mathrm{G}=1,2
$$

$+\sum$. WR $(G) *$ TABLE ELECUSE $($ WR,$(G)$

$$
\mathrm{G}=1,2
$$

c. Balance equations insure equality between the inputs and outputs of burning and grinding processes.

$$
\left.\operatorname{BCEP}(K L): \sum \operatorname{CEP}(K L) I E F\right)=\operatorname{CEP}(K L)
$$

IEF

BCEP: $\quad \sum \operatorname{CEP}(K L)=\mathrm{CEP}$

Ki்

BGRDCEP: $\quad$ CEP $=\Sigma \quad \operatorname{CEP}(G)$

$$
\mathrm{G}=1,2
$$

BGRDWR: $\quad W R=\Sigma \quad W R(G)$

$$
\mathrm{G}=1,2
$$


d. Limiting equations define the constraints on the installed capacity of new kilns (types 07,08 and 09, 10). For example, kilns 07,08 are only built to replace the energy intensive kilns 01, 03, 05; therefore, the equation reads:

$$
\begin{aligned}
& \text { LIMYYKLI: } \quad \sum Y Y(K L)(I E F)+\sum A Y(K L) C O A \leq \\
& \text { IEF, } \quad \mathrm{KL}=03,05 \\
& \mathrm{KL}=01,03,05,07,08 \\
& \sum \text { TABLE KILNINP(( IEF), (KL)) } \\
& \mathrm{KL}=01,03,05 \text {, } \\
& \text { IEF }
\end{aligned}
$$

The same reasoning applies to kilns 09, 10, which replace kiln types $02,04,06$.

The oil and gas burning kilns $03,04,05,06$ can be converted to burn coal.

$$
\begin{aligned}
\operatorname{LIMAY}(\mathrm{KL}) & : \Sigma \mathrm{YY}(\mathrm{KL})(\mathrm{IEF})+\mathrm{AY}(\mathrm{KL}) \mathrm{COA} \leq \Sigma \text { TABLE } \\
& \text { IEF } \neq \mathrm{COA} \\
& \text { IEF } \neq \mathrm{COA} \\
& \text { KILNINP }((\mathrm{IEF}),(\mathrm{KL}))
\end{aligned}
$$

e. Utilization equations represent the plant factors of each kiln. They read

$$
\begin{aligned}
\operatorname{UTIL}(K L) I E F): & \operatorname{CEP}(K L)(I E F) \leq \text { TABLE KILNCAP }(\mathrm{PLF},(\mathrm{KL})) \\
& *(Y Y(K L)(I E F)+A Y(K L)(I E F))
\end{aligned}
$$

f. Ratio equations limit the percentage usage of coal in the cement production or the waste proportion of the cementproduct. They are 


$$
\begin{aligned}
& \operatorname{RCE}(\mathrm{BD})=\frac{\mathrm{TCOACE}}{\sum \mathrm{T}(\mathrm{IEF}) \mathrm{CE}} \leq \mathrm{TABLE} \operatorname{RATIOB}((\mathrm{BD}), \mathrm{CE}) \\
& \mathrm{IEF} \\
& \mathrm{RD} 1(\mathrm{BD})=\frac{\mathrm{WR} 1}{\mathrm{WR} 1+\mathrm{CEP} 1} \leq \mathrm{TABLE} \operatorname{RATIOD}((\mathrm{BD}), 1) \\
& \mathrm{RD} 2(\mathrm{BD})=\frac{\mathrm{WR} 2}{\mathrm{WR} 2+\mathrm{CEP} 2}-\leq \mathrm{TABLE} \operatorname{RATIOD}((\mathrm{BD}), 2) \\
& \mathrm{RD} 3(\mathrm{BD})=\frac{\mathrm{CEP} 2+\mathrm{WR} 2}{\mathrm{CP}+\mathrm{WR}}-\leq \mathrm{TABLE} \operatorname{RATIOD}((\mathrm{BD}), \mathrm{D} 3)
\end{aligned}
$$

9. Objective function entries account for the total cost involved in cement manufacture. Included are the capital cost of the new kilns built, the fuel cost and operating and maintenance charges of all kilns. Also charged is the cost of conversion to coal burning. 
MULTI-REGIONAL MODEL

In order to model the electrical sector more realistically, a study was performed of a formulation in which the year is divided into three seasons (winter, summer, spring/fall) and two daily divisions (day, night). This more flexible approach allows the model to choose whether a summer or winter peak will occur and better depicts the yearly time dependence of demands. This is important since in the sourcebook (2), replication of the RES's yields a summer peak in 1972 and a winter peak in succeeding years.

Six basic demand types were defined: base load, intermediate load (daytime), daily off-peak (nighttime), winter, summer, and fall/spring. Each type has its own set of demand characteristics regarding its peak fraction and its seasonal (winter, summer, spring/fall) and daily (day, night) loading. Required capacity is governed by the highest total peak demand which regionally occurs during some time of the year and day. By characterizing the demand categories as to percent of demand belonging to each demand type and the demand types (inclusive of peaking requirements) according to season-day combinations in which the demand type occurs, height of the total peak for each season-day can be determined. Required capacity is simply the maximum of all the individual season-day peaks with allowances made for regional transmission efficiencies and reserve margins. 
The demand types were characterized by the seasons and daily divisions in which they occurred as follows ${ }^{*}$ :

Table $B-1$

\begin{tabular}{|c|c|c|c|c|c|c|c|}
\hline & & WD & WN & SD & - SN & FD & FN \\
\hline BL & Base load & $4 / 24$ & $4 / 24$ & $3 / 24$ & $3 / 24$ & $5 / 24$ & $5 / 24$ \\
\hline IL & Intermediate load & $4 / 12$ & 0 & $3 / 12$ & 0 & $5 / 12$ & 0 \\
\hline DO & Daily off-peak & 0 & $4 / 12$ & 0 & $3 / 12$ & 0 & $5 / 12$ \\
\hline WH & Winter & $1 / 2$ & $1 / 2$ & 0 & 0 & 0 & 0 \\
\hline SC & Summer & 0 & 0 & $1 / 2$ & $1 / 2$ & 0 & 0 \\
\hline FS & Fall/spring & 0 & 0 & 0 & 0 & $1 / 2$ & $1 / 2$ \\
\hline
\end{tabular}

It is assumed that the fraction of demand occurring in a given season/daily division demand type is proportional to the length of that season/daily division. Thus, 5/24 of a demand characterized as demand type base load will occur during a fall/ spring day. Of course, a final demand, such as miscellaneous commercial electric, does not have to be characterized as a pure demand type: the load curve can be defined in as detailed a manner as desired by specifying the fractions of final demand that belong to each of the different demand types. To illustrate, the study employed 24 different final demands tabulated for the regional Reference Energy Systems (room and central air conditioning, and aluminum electrolysis and drive are disaggregated in the fuel mix tables). These demands are characterized by the

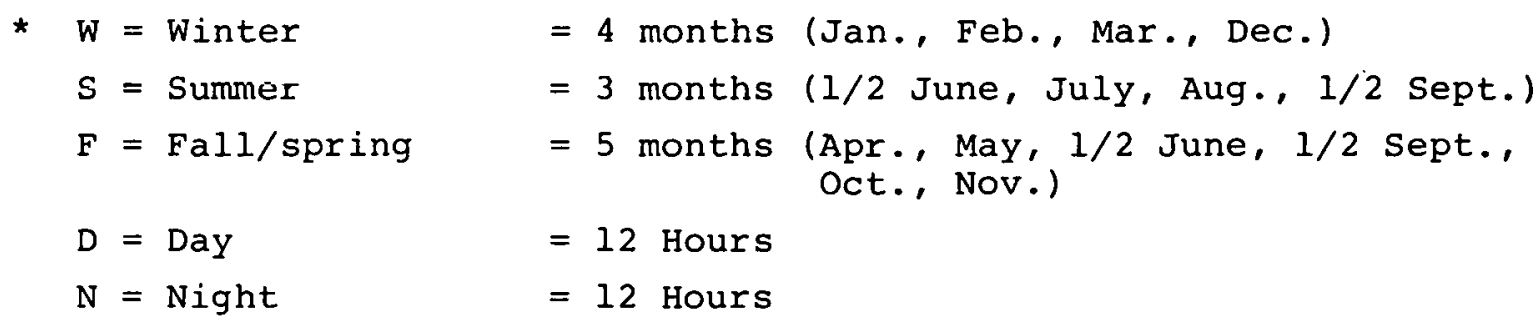


fraction belonging to each demand category as shown in Tables B-2 and $B-3$. Regional variation in space conditioning demands is shown in Table $\mathrm{B}-2$.

Table B-2

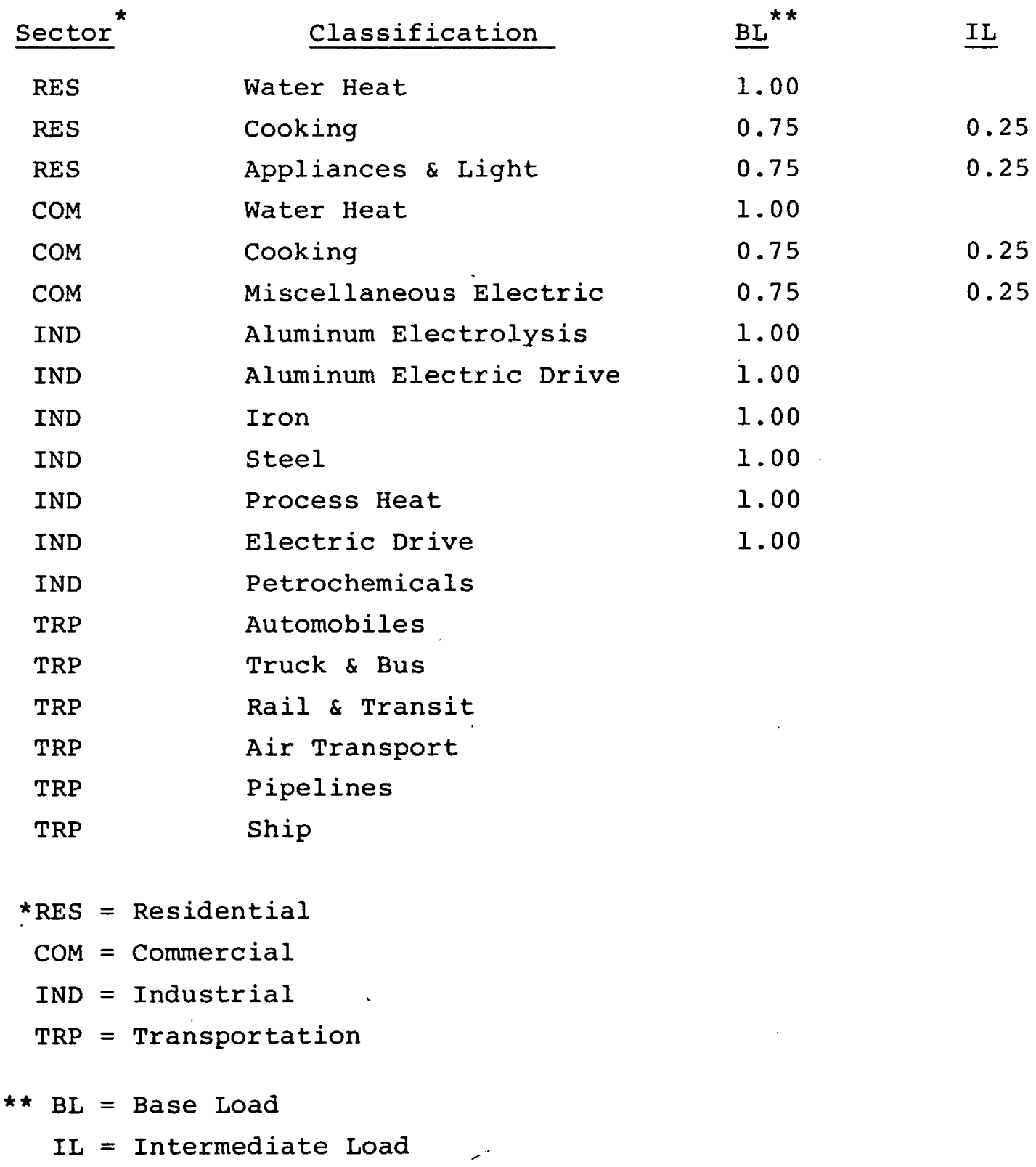


Table $B-3$ Residential \& Commercial
Space Heat

\section{Region}

1. New England (NE)

2. Middle Atlantic (MA)

3. East North Central (ENC)

4. West North Central (WNC)

5. South Atlantic (SA)

6. East South Central (ESC)

7. West South Central (WSC)

8. Mountain (MT)

9. Pacific PAC)

\begin{abstract}
WH
\end{abstract}
0.65

sc

0.70

0.01

$\underline{F S}$

0.34

0.30

0.67

0.01

0.32

0.69

0.01

0.30

0.76

0.75

0.82

0.64

0.64

0.24

0.25

0.18

0.35

0.36
Residential \& Commercial Air Conditioning (Room and Central)

$\underline{\text { WH }}$ $\underline{\mathrm{SC}}$

FS

1.00

1.00

0.95

0.05

0.90

0.10

$0.79 \quad 0.21$

$0.80 \quad 0.20$

0.71

0.29

0.93

0.07

1.00

WH $=$ Winter (Jan., Feb., Mar., Dec.)

$\mathrm{SC}=$ Summer $(1 / 2$ June, July, Aug., 1/2 Sept. $)$

FS $=$ Fall/spring (Apr., May, 1/2 June, 1/2 Sept., Oct., Nov.) 
The methodology for computing the fractions was as follows: Climatological data by regions (approximately 10) in each state for a five-year period were weighted to the respective region's percent of the total state's population. Furthermore, the state's weighted degree-day demand was weighted within its region by the ratio of state to regional population. The basis was $68^{\circ}$. The results for each region are shown in Table $B-4$.

Each of the demand types was also characterized by its "peak fraction", the amount contributing to the endogenous peak demand. This formulation is used in BESOM. The peak fractions were assumed to be the same as used in standard runs of BESOM. The new formulation was tested, for 1972, using a reserve margin of $20 \%$. The results were that in every region the peak demand occurred during the summer day. Total capaci'ty required was 408.6 GWe as opposed to the sourcebook total of 399.5. If a reserve margin factor of $18 \%$ had been used, the result would have been 401.8 , or an error of $0.6 \%$. It was concluded that the formulation and demand type characterization of demand categories were valid. 
Table B-4(a)

HEATING DEGREE DAYS

$$
68^{\circ} \text { BASE }
$$

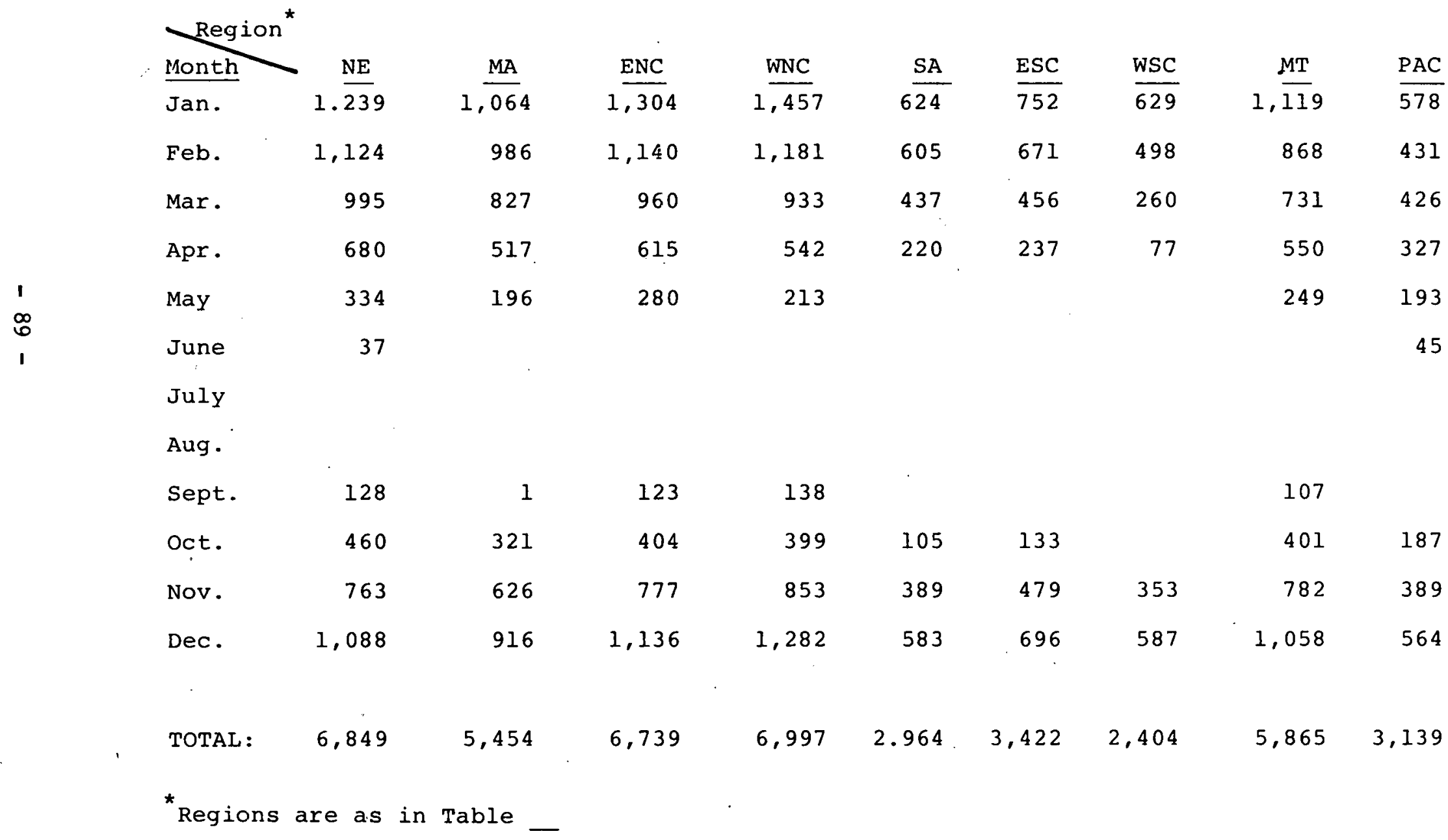


Table B-4(b)

COOLING DEGREE DAYS

$$
68^{\circ} \text { BASE }
$$

Region

Month

NE.

MA

ENC

WNC

$\underline{\text { SA }} \quad \underline{E S C} \quad \underline{W S C}$

$\underline{M T} \quad \underline{P A C}$

Jan.

Feb.

Mar .

Apr .

May

June

July

156

$34 \quad 105$

25

๖

Aug.

120

245

153

227

222

$15 \quad 159$

sept.

124

173

320

240

352

68

oct.

Nov.

Dec .

TOTAL 